\title{
Strain hardening behaviour of as-quenched and tempered martensite
}

\author{
L.Y. Wang ${ }^{1}$, Y.X. Wu ${ }^{1}$, W.W. Sun ${ }^{1,2}$, Y. Bréchet ${ }^{1}$, L. Brassart ${ }^{1,3}$, A. Arlazarov ${ }^{4}$, C.R. Hutchinson ${ }^{1 *}$ \\ ${ }^{1}$ Department of Materials Science and Engineering, Monash University, Clayton, VIC 3800, Australia \\ ${ }^{2}$ School of Materials Science and Engineering, Southeast University, Nanjing 211189, China \\ ${ }^{3}$ Department of Engineering Science, University of Oxford, Oxford OX1 3PJ, United Kingdom \\ ${ }^{4}$ ArcelorMittal Global Research and Development, Voie Romaine-BP30320, 57283, Maizières-les-Metz, \\ France
}

*Corresponding Author: christopher.hutchinson@monash.edu

Keywords: Martensite, tempered martensite, advanced high strength steels (AHSS), strengthening mechanism, Bauschinger test, composite model, residual stress relaxation

\begin{abstract}
Martensite is a key constituent in advanced high strength steels and plays an important role in providing the high strength. While the strength of martensite has been extensively studied in the past, its low elastic limit and extremely high strain hardening rate remain a puzzle for the steel community. Composite models proposed recently can successfully reproduce these features as result of gradual yielding of microstructural constituents with either variations in intrinsic yield strengths or transformation induced residual stresses. Although these composite models can explain certain observations associated with the deformation of as-quenched martensite, neither can self-consistently describe all the key characteristics in the tension-compression behaviour of asquenched martensite. Attempts to extend these composite models to tempered martensite have been limited. In this contribution, we conduct a systematic experimental study on the strain hardening of as-quenched and tempered martensite with mechanical testing (e.g. monotonic tension and tension-compression) and interrupted X-ray diffraction. It is shown that the high strain hardening rate, large Bauschinger effect and diffraction line narrowing found in as-quenched martensite during straining can be sustained in tempered martensite tempered up to $400^{\circ} \mathrm{C}$. These phenomena can be understood by considering martensite as a multi-constituent composite having both variations in intrinsic yield strengths and relaxation of transformation induced residual stresses during straining.
\end{abstract}




\section{Introduction}

Recent developments in advanced high strength steels (AHSS) have sparked renewed interests in understanding the strength and plasticity of martensite. Historically, studies on martensite focused mainly on the correlation between its $0.2 \%$ proof strength and microstructural features. It is well known that the change of bulk carbon content [1-4], substructure sizes [5-8] and dislocation densities [3,9,10] all affect the strength of martensite. However, it is not sufficient to understand only the evolution of the yield, or proof, strength in the context of AHSS development, since the martensite often undergoes plasticity in AHSS's [11-13] and hence its strain hardening behaviour and ductility are also relevant.

Even though as-quenched martensite with low/medium carbon content shows a high ultimate tensile strength (up to $2000 \mathrm{MPa}$ ), its flow behaviour is characterised by a low elastic limit ( $\sim 300-500 \mathrm{MPa}$ ) and a continuous, extended elastic-plastic transition [14-17]. Consequently, the strain hardening rate of as-quenched martensite can be extremely high and exceed the limit for the dislocation storage mechanism ( E/50) [18]. Previous studies have attributed the micro-yielding phenomenon to the presence of microstructural weak points such as mobile dislocations [19-21] and retained austenite [15,22-26]. During straining, the multiplication and entanglement of mobile dislocations and strain-induced transformation of austenite contribute to the observed high strain hardening rate. Although these microstructural features do exist in most martensitic steels, they will only contribute to strain hardening in the first one or two percent strain as they are easily exhausted by plasticity $[21,23]$. Recent investigations using atom probe tomography (APT) have also shown that most dislocations in $\mathrm{Fe}-\mathrm{C}$ martensite are heavily segregated with carbon and may not be mobile during deformation [4,27]. The fact that the high strain hardening rate can be sustained to the point of necking (typically $3-4 \%$ in low/medium carbon martensite) requires further explanation.

New interpretations developed recently have demonstrated that the continuous yielding of as-quenched martensite can be better understood as a multi-constituent composite, in the spirit of Masing [28] and Asaro [29]. In these theories, the strain hardening is caused not by dislocation multiplication but by the gradual yielding of constituents. Allain et al. proposed that if there is an intrinsic variation in the yield strengths of the constituents, the soft constituents would yield first and contribute to the low elastic limit [17], and the harder constituents would yield continuously and result in the high strain hardening rate. The authors attributed the spread in the yield strengths to the heterogeneous carbon distribution within martensite and this has been shown qualitatively to exist by atom probe tomography $[4,27,30]$. Whilst this "continuous composite approach" (CCA) is able to describe the tensile and Bauschinger behaviour of as-quenched martensite, nanoindentation experiments designed to probe the distribution in local yield strengths, have found it difficult to rationalise the large variation required in the models to reproduce the flow results [27,31-33]. Allain and co-workers have found the experimental variation in nanohardness to be $\sim 25 \%$ of the spread required in the model [33]. This is one of the weaknesses of the CCA. 
Hutchinson and co-workers have developed a similar composite model based on a distribution of Type II residual stresses remaining from the martensitic transformation itself [34,35]. This hypothesis was first proposed by Muir et al. [14] in the 1950s but rationalised by mathematical models only recently by Hutchinson $[34,35]$. When residual stresses are oriented toward or against the uniaxial tensile direction, they can either facilitate or resist the onset of local plasticity even if all constituents share the same yield strength. Consequently, the reported diffraction line narrowing [20,36,37] and peak asymmetry [38,39] in diffraction experiments after deformation are not necessarily attributed to a reduction in dislocation densities [20,36] but instead are a direct result of residual stress relaxation and heterogeneous elastic strain development within individual constituents. Hutchinson et al. have demonstrated the capability of this model in describing the monotonic tension behaviour of as-quenched martensite [34,35]. However, this model would predict the Bauschinger effect disappears at larger strains.

As will be shown, the CCA lacks the ability to explain the diffraction peak narrowing phenomenon, in addition to the outstanding question regarding the width of the yield strength distribution required to reproduce the experimental observations. The residual stress model of Hutchinson et al. can provide a suitable explanation for the diffraction line narrowing and asymmetry, but if the residual stresses are allowed to relax fully during forward loading and hardening contributions from dislocation evolutions are discounted, the material should not show any significant Bauschinger effect, which contradicts the experimental results [17,40]. Both approaches, the CCA and residual stress model, are able to explain certain observations associated with the deformation of as-quenched martensite, but neither can self-consistently describe all the key characteristics.

The situation is further complicated if we consider the flow behaviour of tempered martensite. Almost all martensite constituents in AHSS are tempered or heavily auto-tempered during the quenching process. This is especially true in the case of quenching and partitioning (Q\&P) steel where the material is subjected to a partitioning process at temperatures up to $400^{\circ} \mathrm{C}$ [41]. The final transformed product comprises tempered martensite, retained austenite and fresh martensite. Therefore, it is important to develop understandings for both as-quenched and tempered martensite. Although the mechanical response of low temperature tempered martensite (temperatures around $200^{\circ} \mathrm{C}-400^{\circ} \mathrm{C}$ ) has been studied extensively [1,42-45], theoretical treatments on the flow behavior are limited and focused mainly on monotonic tension [46-49].

The objective of this contribution is to study the deformation mechanisms of both as-quenched and low temperature tempered martensite and to develop quantitative models to describe the flow behavior during tension and Bauschinger tests. The experimental campaign examines the flow behaviour of martensite using monotonic tension tests and Bauschinger tests, complemented with interrupted X-ray diffraction. For asquenched and low temperature tempered martensite $\left(300^{\circ} \mathrm{C}\right.$ and $\left.400^{\circ} \mathrm{C}\right)$, it will be demonstrated that the experimental results can be understood when the two composite models are integrated to include both 
variations in intrinsic yield strengths, the relaxation of residual stresses during straining and incompatibility stresses resulting from differential yielding.

\section{Experimental procedure}

The materials used in this study were provided by ArcelorMittal and their compositions are shown in Table 1 . The base composition is Fe- $0.25 \mathrm{C}-2.5 \mathrm{Mn}$ (wt. \%) which allows the steel to be water quenched to form a fully martensitic matrix. Si and $\mathrm{Al}$ were added to control the kinetics of cementite precipitation during tempering. The steels have been provided as both cold rolled (CR) sheets $(\sim 1.2 \mathrm{~mm}$ thick) and hot rolled (HR) plates $(\sim 6$ $\mathrm{mm}$ thick). The cold rolled sheets were used for monotonic tensile tests and X-ray diffraction experiments and the hot rolled plates were used to perform tension-compression Bauschinger tests. The austenitisation experiments were conducted in a horizontal tube furnace heated to $950{ }^{\circ} \mathrm{C}$ with flowing $\mathrm{Ar}$ for 10 minutes followed by water quenching. The tempering experiments were performed in a salt bath $\left(300^{\circ} \mathrm{C}\right.$ and $\left.400^{\circ} \mathrm{C}\right)$ for various times and the samples were water quenched after tempering.

Table 1 The chemical compositions of the investigated steels (wt.\%)

\begin{tabular}{lllllllll}
\hline Designation (reference composition) & & Fe & C & Mn & Si & Al & P & S \\
\hline \multirow{2}{*}{ Base steel (Fe-0.25C-2.5Mn) } & CR & Bal. & 0.24 & 2.4 & $<0.02$ & 0.01 & 0.01 & 0.01 \\
& HR & Bal. & 0.25 & 2.43 & $<0.02$ & 0.01 & 0.01 & 0.01 \\
Si steel (Fe-0.25C-2.5Mn-1.4Si) & CR & Bal. & 0.25 & 2.42 & 1.44 & 0.01 & 0.01 & 0.01 \\
& HR & Bal. & 0.24 & 2.4 & 1.45 & 0.01 & 0.01 & 0.01 \\
Al steel (Fe-0.25C-2.5Mn-1.4Al) & CR & Bal. & 0.27 & 2.46 & 0.02 & 1.38 & 0.01 & 0.01 \\
& HR & Bal. & 0.26 & 2.52 & 0.02 & 1.42 & 0.01 & 0.01
\end{tabular}

Monotonic tension tests were conducted on an Instron 4505 screw-driven machine with a $100 \mathrm{kN}$ load capacity and the strain was measured using a clip-on extensometer with a gauge length of $10 \mathrm{~mm}$. The crosshead speed during tensile tests was fixed to be $0.02 \mathrm{~mm} / \mathrm{s}$ (equivalent strain-rate $\sim 1.67 \times 10^{-3} \mathrm{~s}^{-1}$ ). Samples with a parallel length of $12 \mathrm{~mm}$ and a gauge width of $5 \mathrm{~mm}$ were electrodischarge machined from the cold rolled sheets parallel to the rolling direction. Sample surfaces were cleaned using \#1200 grit sandpaper before testing so that any effect of decarburisation and/or nitriding (from the salt bath) after heat treatments were eliminated.

Tension-compression tests were performed to verify the capability of models in describing the Bauschinger effect in martensite. The tests were conducted using a servo-hydraulic MTS Landmark machine with a $100 \mathrm{kN}$ load capacity. The alignment of the testing system was calibrated to be close to ASTM E1012 Class 5 using the MTS 609 alignment fixture and a standard sample with 12 strain gauges before each set of tests. Samples with a parallel length of $18 \mathrm{~mm}$ and a gauge diameter of $4.5 \mathrm{~mm}$ were machined from the HR plates with their 
longitudinal directions parallel to the rolling direction. The final machining was conducted after heat treatments so that macroscopic residual stresses at sample surfaces were removed. Monotonic tension tests were conducted with a constant crosshead speed of $0.03 \mathrm{~mm} / \mathrm{s}$ (equivalent strain-rate $\sim 1.67 \times 10^{-3} \mathrm{~s}^{-1}$ ) and one clipon extensometer with a gauge length of $10 \mathrm{~mm}$ was used to record the strain during monotonic tests. Tensioncompression tests were conducted with the same crosshead speed, but with two clip-on extensometers mounted diametrically opposed to each other. This setup was used so that buckling during compression can be identified when the readings from the two extensometers deviate from each other significantly [50-52].

X-ray diffraction (XRD) was used to investigate the peak profile of as-quenched and tempered martensite before and after deformation. Samples were cut from either the undeformed head or the deformed gauge section of the CR tensile samples and polished to $0.05 \mu \mathrm{m}$ surface finish with colloidal silica. The XRD experiments were conducted on a Bruker D8 Advance diffractometer with a Co tube (operated at $40 \mathrm{kV}$ and $25 \mathrm{~mA}$ ) under the Bragg-Brentano geometry. Co source emission profiles, zero error and instrument profiles were assessed from the scan of the NIST $\mathrm{LaB}_{6}$ specimen. X-ray scans were performed over the $38^{\circ} \sim 132^{\circ} 2 \theta$ range at a step size of $0.03^{\circ}$ to capture four diffraction peaks. Line profile analyses of XRD patterns was performed in the Bruker-TOPAS (version 5) software using the whole-pattern Pawley method. Since peak splitting was not observed in the low carbon martensite studied in this work, the peaks were refined with a body centre cubic (BCC) lattice structure instead of body centre tetragonal (BCT). Peak broadening of BCC reflections was modelled using Balzar's double-Voigt approach [53] that considers convoluted Voigt functions of the Gaussian and the Lorentzian components that can be refined to describe the domain size broadening and the microstrain broadening, respectively. In this study, the microstrain is used to describe the magnitude of peak broadening instead of the full width half maximum (FWHM) used in some previous works [34-36]. It should be noted that the intention of this work is to use the changes in diffraction peaks to explore the evolution of the transformation induced residual stresses and the simple double-Voigt approach seems sufficient for the purpose. This is a relatively simple method for line profile analysis and may not reflect the detailed evolution of dislocations during straining. More advanced line profile methods such as the modified Williams-Hall and Warren-Averbach methods $[21,54,55]$ and the convolutional multiple whole profile method $[38,39,56]$ should be used if the evolution of dislocation density and arrangement is the main interest. 


\section{Results}

\subsection{Strain hardening studied using monotonic tension tests}

Figure 1a, c and e show the true stress - true strain curves for the base, Si and Al steels in both the as-quenched state and as a function of tempering. The Si steel generally shows a higher strength than the base steel due to the solid solution strengthening effect of Si. The lower strength of the Al steel at all heat treatment conditions is largely attributed to its larger prior austenite grain size ( $\sim 20 \mu \mathrm{m}$ compared to $\sim 8 \mu \mathrm{m}$ for the base and Si steels). For all compositions, tensile curves for the as-quenched condition start to deviate from linearity at $400 \mathrm{MPa}$ to $500 \mathrm{MPa}$, which is in agreement with previous reports [17]. After tempering, the elastic-plastic transition becomes much narrower and yield points are clearly visible. The ultimate tensile strengths (UTS) of tempered samples witness a significant drop after tempering. The uniform elongations decrease due to the temper induced embrittlement effect at $300^{\circ} \mathrm{C}$ to $400^{\circ} \mathrm{C}$ [57].

The strain hardening behaviour of tempered martensite can be clearly shown when plotting the strain hardening rate versus the true stress in Figure $1 \mathrm{~b}, \mathrm{~d}$ and $\mathrm{f}$. The strain hardening rates of the as-quenched states are much larger than the tempered states and are always higher than the E/50 limit for dislocation storage based mechanisms. The E/50 limit is met until $\sim 3 \%$ of the total strain which results in the extended elastic-plastic transition shown in the tensile curves. The strain hardening rates decrease as a function of annealing temperatures and times. For low temperature tempered samples, the strain hardening rates after the yield discontinuities share a similar slope with the as-quenched condition and a significant portion of the curve is above the E/50 limit. The limit is reached at $\sim 1.5 \%$ to $2 \%$ in the tempered samples and suggests that the same strain hardening mechanism governs the behaviour of as-quenched martensite as well as the martensite tempered at low temperatures of $300^{\circ} \mathrm{C}$ and $400^{\circ} \mathrm{C}$. 

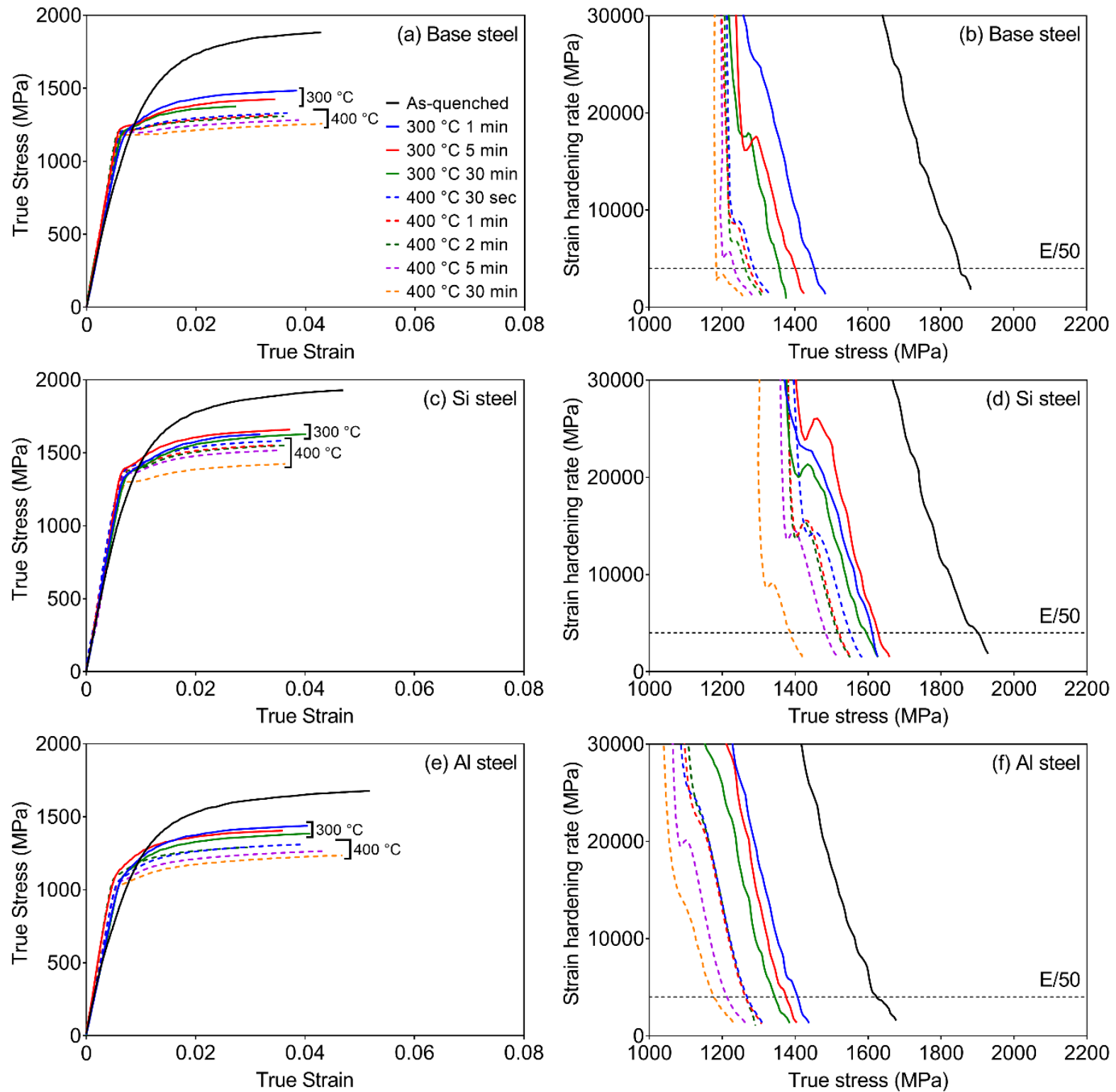

Figure 1 True stress - true strain and strain hardening rate - true stress curves for the base steel (a and b), the Si steel (c and d) and the Al steel (e and f) with different heat treatment conditions.

\subsection{Bauschinger effect studied using tension-compression tests}

Figure 2a shows typical tension and tension-compression curves from an as-quenched martensite sample. The sample was first strained to a forward strain to achieve a forward stress $\sigma_{f}$ and then compressed until the point of buckling. The reverse yield stress $\sigma_{r}$ is found using a $0.2 \%$ offset strain [58-60] and it is much smaller than $\sigma_{f}$, indicating a pronounced Bauschinger effect. The Bauschinger effect can be quantified by the back stress $\sigma_{b}$ which is defined as $\sigma_{b}=\left(\sigma_{f}-\left|\sigma_{r}\right|\right) / 2[50,51,61]$. Figure $2 \mathrm{~b}-\mathrm{d}$ shows that tempering at $300^{\circ} \mathrm{C}$ and $400^{\circ} \mathrm{C}$ does not lead to a significant change in the magnitude and development of the back stress until the samples are tempered at $400^{\circ} \mathrm{C}$ for 1 hour. It further supports the hypothesis made previously that the dominant strain hardening mechanism in as-quenched martensite does not change after low temperature tempering. 

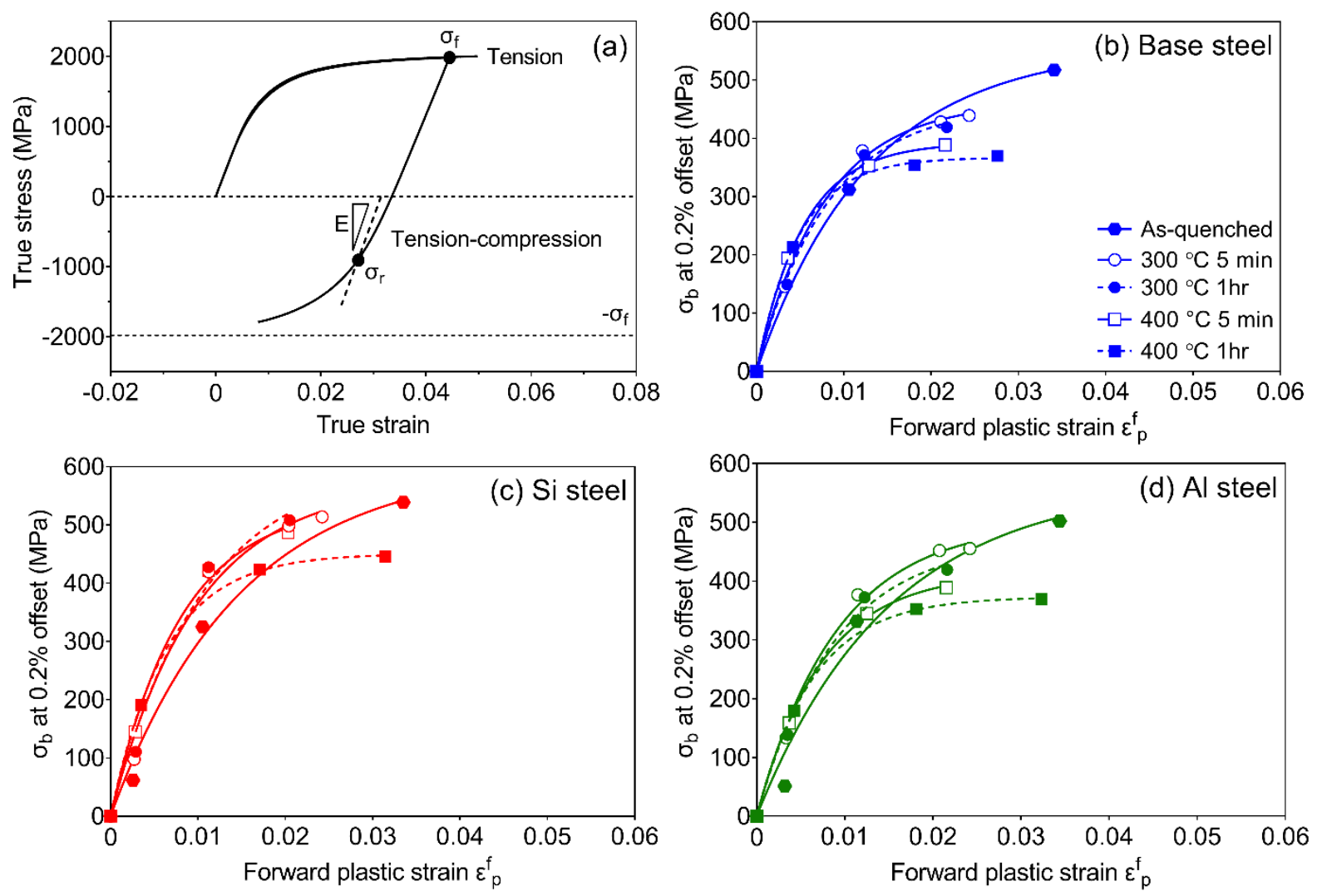

Figure 2 Bauschinger effect in martensite. (a) Example tension and tension-compression curve in as-quenched $\mathrm{Si}$ steel samples. (b) - (d) Evolution of back stress as a function of forward plastic strains. The continuous lines are obtained by fitting the experimental back stress data with the phenomenological non-linear kinematic hardening model $\left(\sigma_{b}=2 / 3 \cdot C_{\xi} / \xi \cdot \exp \left(-\xi \varepsilon_{p}\right), C_{\xi}\right.$ describes the effective hardening modulus and $\xi$ takes into account the dynamic recovery of hardening) [62].

\subsection{Residual stress relaxation studied using interrupted X-ray diffraction}

A key characteristic accompanying the deformation behaviour of as-quenched martensite is the narrowing of diffraction lines during straining[34-36,38,39]. Since the strain hardening rates for $300^{\circ} \mathrm{C}$ and $400^{\circ} \mathrm{C}$ tempered samples show values comparable to the as-quenched state, one should ask if the diffraction line narrowing phenomenon is still visible if interrupted X-ray diffraction experiments are performed.

Figure $3 \mathrm{a}-\mathrm{c}$ show the effect of tempering and straining on the evolution of microstrain measured from the diffraction experiments. To the left of the vertical dashed line, the figures show that tempering leads to a decrease in microstrain. Whilst all compositions share a similar level of microstrain in the as-quenched state, the addition of $\mathrm{Si}$ and $\mathrm{Al}$ (Figure $3 \mathrm{~b}$ and c) clearly reduces the magnitude of the microstrain drop after tempering at $300^{\circ} \mathrm{C}$ and $400^{\circ} \mathrm{C}$. To the right of the dashed line, the figures show the effect of monotonic straining. For each tempering condition, several interrupted tests were performed and the maximum forward strain was set approximately $0.5 \%$ to $1 \%$ below the uniform elongation of each condition. This ensures that strain localisation as result of necking does not affect the microstrain measurements. 

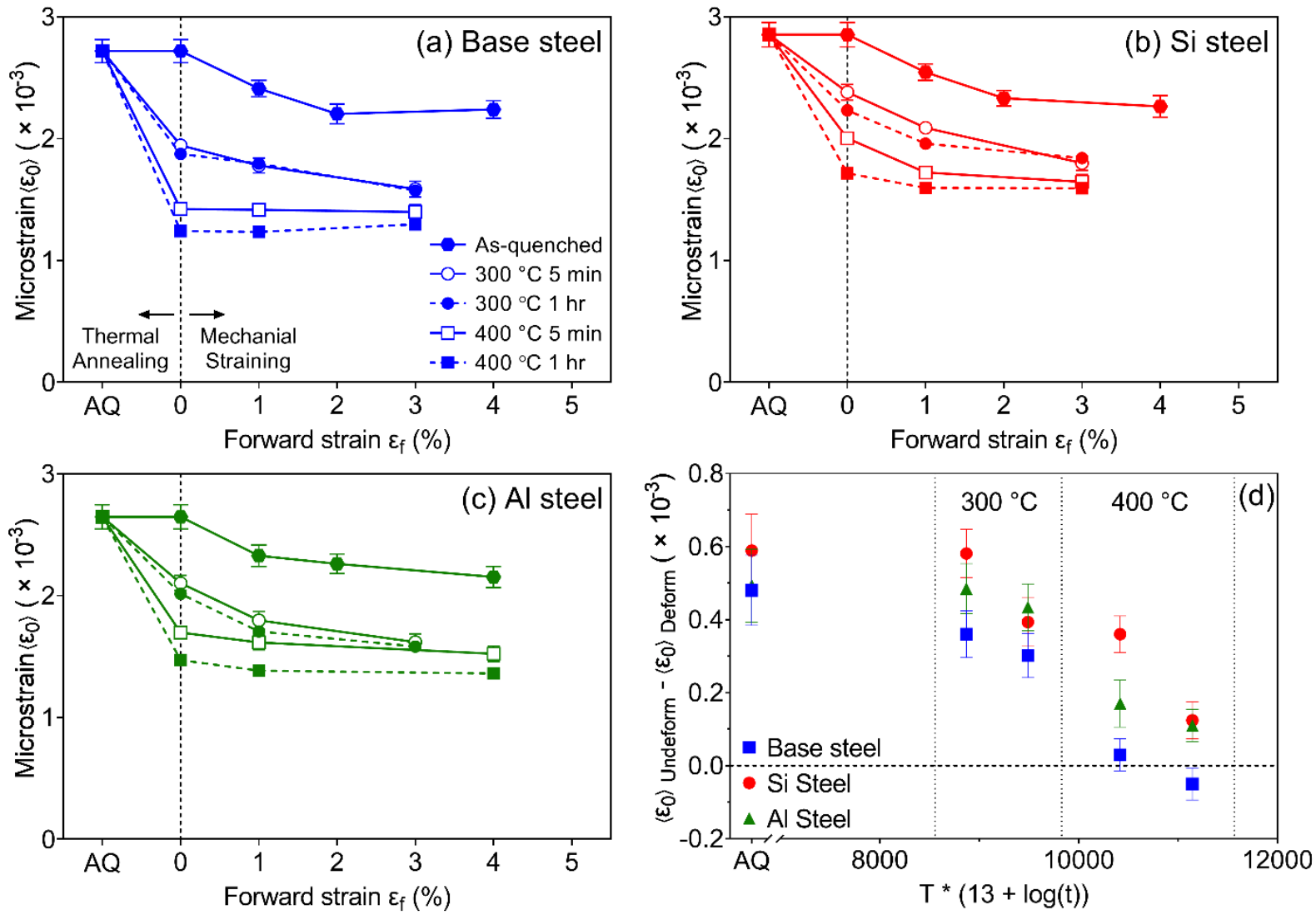

Figure 3 Evolution of microstrain as a function of straining for the base steel (a), the Si steel (b) and the Al steel (c) tempered at different temperatures for 5 minutes (open symbols) and 1 hour (solid symbols). (d) Hollomon-Jaffe plot [63] showing the evolution of the magnitude of the microstrain reduction after deformation for the $300^{\circ} \mathrm{C}$ and $400^{\circ} \mathrm{C}$ tempered samples. At each temperature, two tempering times are shown (i.e. 5 minutes and 1 hour). Error bars in all plots represent two times the Rietveld error.

According to the model proposed by Hutchinson et al., diffraction line narrowing is a result of residual stress relaxation during straining $[34,35,64]$. The fact that $300^{\circ} \mathrm{C}$ and $400^{\circ} \mathrm{C}$ tempered samples still show line narrowing implies that residual stresses cannot be fully relaxed by thermal treatments at low temperatures and some of the residual stresses remain to be relaxed by plastic straining. Moreover, prolonged tempering at $300^{\circ} \mathrm{C}$ and $400^{\circ} \mathrm{C}$ does not influence significantly the line narrowing behaviour during deformation (solid symbols in Figure $3 \mathrm{a}-\mathrm{c}$ ) but it does reduce the magnitude of the narrowing (expressed as the difference between the microstrain before $\left\langle\varepsilon_{0}\right\rangle_{\text {Undeform }}$ and after $\left\langle\varepsilon_{0}\right\rangle_{\text {deform }}$ deformation to strains close to UTS, Figure $3 \mathrm{~d}$ ). This suggests that the long-time tempering at low temperatures leads to further relaxation of residual stresses. The addition of $\mathrm{Si}$ and $\mathrm{Al}$ affects the relaxation process and their effect is most clearly seen in samples tempered at $400^{\circ} \mathrm{C}$. While the base steel displays limited relaxation and even line broadening during deformation after tempering at $400^{\circ} \mathrm{C}$, a considerable amount of residual stresses remains in the alloyed samples even after tempering at $400^{\circ} \mathrm{C}$ for $1 \mathrm{~h}$. 


\section{Modelling the flow behaviour of as-quenched and low temperature tempered martensite}

In this section, we focus on the explanation of the strain hardening behaviour and the Bauschinger effect for as-quenched and low temperature tempered martensite using composite models. The two classes of composite models reviewed in the introduction are first compared and then combined to consider both the distribution in intrinsic yield stresses and the relaxation of the transformation induced residual stresses during straining. The results of the model are compared with the tension-compression experimental data to demonstrate the capabilities of the models to describe both the forward and reverse flow behaviours of martensite.

\subsection{Introduction to the unified modelling framework}

The model proposed by Allain et al. will be referred to as the "yield stress spectrum model" [17] and the model proposed by Hutchinson et al. will be termed the "residual stress spectrum model" [34,35]. In essence, both models consider as-quenched martensite as a composite but the gradual yielding of composite constituents are related to different initial states: the "yield stress spectrum model" assumes that as-quenched martensite comprises constituents with different yield stresses that may be described by a continuous yield stress spectrum [17]; the "residual stress spectrum model" considers that the constituents in martensite share a similar yield stress but each constituent is affected by an initial residual stress that may vary locally as a result of the martensitic transformation [34,35]. The two models also differ in the implementation of incremental straining and strain partitioning. It is difficult to differentiate the two models on the basis of the tensile curve only, but they will differ in their abilities to describe the tension-compression behaviour and the evolution of the diffraction line during straining.

In the present work, we have developed a framework which includes initialisation schemes for both composite models and a unified incremental straining scheme describing the transformation induced residual stress relaxation and incapability stress building. The modelled results using this framework can be compared quantitatively with experimental data.

The macroscopic stress-strain response of the composite-like martensite during straining is obtained by averaging over the response of its individual constituents as:

$$
\begin{gathered}
\overline{\boldsymbol{\varepsilon}}=\sum_{i=1}^{n_{c}} V^{i} \boldsymbol{\varepsilon}^{i} \\
\overline{\boldsymbol{\sigma}}=\sum_{i=1}^{n_{c}} V^{i} \boldsymbol{\sigma}^{i}
\end{gathered}
$$

where $n_{c}$ is the total number of constituents, $\overline{\boldsymbol{\varepsilon}}$ and $\overline{\boldsymbol{\sigma}}$ are the average strain and stress, $\boldsymbol{\varepsilon}^{i}$ and $\boldsymbol{\sigma}^{i}$ are the strain and stress tensors of the $i^{\text {th }}$ constituent with a volume fraction $V^{i}$. At this stage, we do not seek to identify a constituent to a specific microstructural feature, such as martensite lath or block. For simplicity, we assume 
that all constituents are subjected to a uniaxial state of stress. Strain partitioning of strain among the constituent is presented in Section 4.2.3.

For the sake of simplicity, the stress-strain response of each constituent is assumed to be elastic, perfectly plastic. The Young's modulus and Poisson's ratio are assumed identical for all constituents: $E=205 \mathrm{GPa}$ and $v=0.3$. The yield stress of the $i^{\text {th }}$ constituent is written $\sigma_{y 0}^{i}$. In the "yield stress spectrum model", constituents have different yield stress, but the initial stress is zero. In the "residual stress spectrum model", all constituents have the same yield stress, but are subjected to different pre-stresses. These different assumptions also affect the determination of $V^{i}$.

In the following, constitutive assumptions for each model are detailed, and the numerical scheme used to calculate the composite response is presented, which is model independent.

\subsection{Constituent behaviour}

\subsubsection{Yield stress spectrum model}

In the "yield stress spectrum model", the onset of plasticity in each constituent is governed solely by its initial yield stress $\sigma_{y 0}^{i}$. From a constitutive modelling perspective, constituents in the "yield stress spectrum model" all start from a zero stress state and they reach their unique yield surfaces at different forward strains (Figure $4 a)$. In a continuous yield stress spectrum, the probability of finding a constituent with a particular yield stress can be found using a probability density function. In the work of Allain et al., a Weibull distribution was assumed [17]:

$$
f\left(\sigma_{y 0}^{i}\right)=\left\{\begin{array}{cc}
0 & \sigma_{y 0}<\sigma_{\min } \\
\frac{n}{\sigma_{0}}\left(\frac{\sigma_{y 0}^{i}-\sigma_{\min }}{\sigma_{0}}\right)^{n-1} & \sigma_{y 0} \geq \sigma_{\min }
\end{array}\right.
$$

$\sigma_{\min }$ is the yield stress of the softest constituent in the composite, $\sigma_{0}$ is the width of the yield stress distribution and $n$ governs the shape of the distribution. While the existence of $\sigma_{\min }$ allows Allain et al. [17] to assign a low yield stress (300 MPa) to the softest constituent to describe the low elastic limit in as-quenched martensite, the shape factor was set arbitrarily and it could be highly correlated with the width factor $\sigma_{0}$. Here, we use a normal distribution which defines the mean $\left(\sigma_{\mu}\right)$ and the standard deviation $\left(\sigma_{s d}\right)$ of the yield stress spectrum and omit the use of $\sigma_{\min }$ :

$$
f\left(\sigma_{y 0}^{i}\right)=\frac{1}{\sqrt{2 \pi \sigma_{s d}^{2}}} \exp \left(-\frac{\sigma_{y 0}^{i}-\sigma_{\mu}}{2 \sigma_{s d}^{2}}\right)
$$

In this model, $\sigma_{s d}$ and $\sigma_{\mu}$ are the two "unknown" variables required to describe the flow behaviour. One drawback of assuming a normal distribution for the yield stress spectrum is that the strengths of soft constituents can reach values close to zero (Figure 4b) which is even smaller than the one assumed in Allain's work. These low yield stress values contradict with experimental results obtained using nanoindentation where the minimum yield stress is $\sim 1 \mathrm{GPa}$ and is considered to be an intrinsic limitation of this model if only the 
variation in yield stress is considered [27,33]. The selection of a normal distribution was a compromise we made in the model initialisation scheme that allowed the "yield stress spectrum model" to be compared with the symmetrical residual stress spectrum used in the "residual stress spectrum model".

In the initialisation step, the continuous normal distribution is discretised with a finite number of bins (Figure $4 b)$. The volume fraction of each constituent is defined as the area under the probability density function within each binning interval and can be approximated with the cumulative density function $F\left(\sigma_{y 0}^{i}\right)$ if the interval size is sufficiently small:

$$
V^{i}=F\left(\sigma_{\text {end }}^{i}\right)-F\left(\sigma_{\text {start }}^{i}\right)
$$

$V^{i}$ is the volume fraction of the constituent, $F\left(\sigma_{\text {end }}^{i}\right)$ is the value of the cumulative density function at the end of the interval and $F\left(\sigma_{\text {start }}^{i}\right)$ is the value of the cumulative density function at the start of the interval. The yield stress of each constituent is approximated as the mid-point of the interval as:

$$
\sigma_{y 0}^{i}=\left(\sigma_{\text {end }}^{i}+\sigma_{\text {start }}^{i}\right) / 2
$$

\subsubsection{Residual stress spectrum model}

In the "residual stress spectrum model", the onset of plasticity in each constituent is not governed solely by its yield stress but is also influenced by its initial residual stress state [34,35]. If the residual stress is aligned towards the loading direction, it will facilitate the yielding of the constituent and if the residual stress is aligned against the loading direction, it will resist the yielding of the constituent. From the continuum mechanics perspective, it is equivalent to assigning each constituent a non-zero, elastic stress/strain state along the loading direction before straining but the constituents share the same yield surface (Figure 4c). The constituent with a positive pre-stress will yield earlier than the constituent with a negative pre-stress. Based on this principle, the model considers a uniaxial residual stress $\left(\sigma_{r s}^{i}\right)$ acting along the loading direction. The initial elastic strain corresponding to the residual stress can be calculated from Hooke's law. 

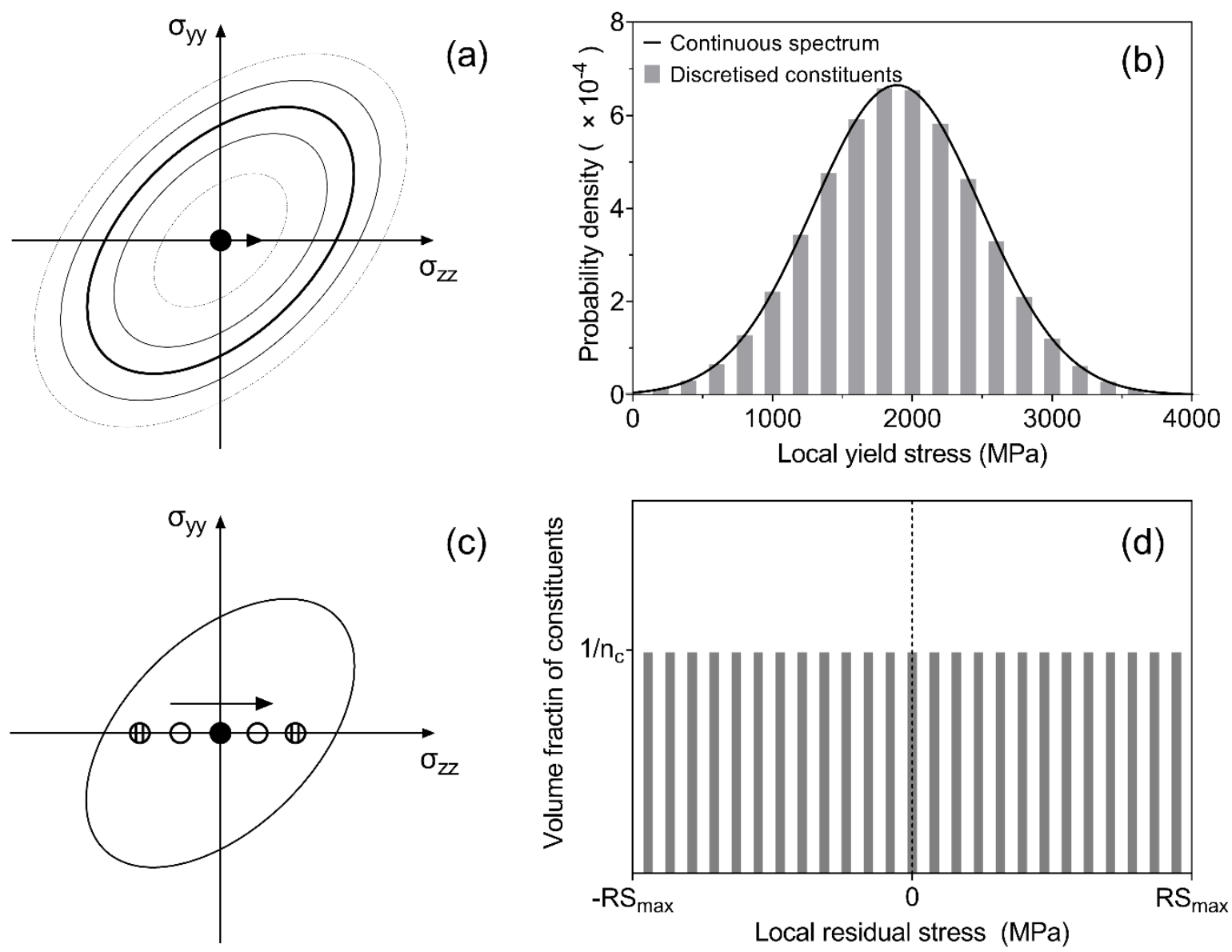

Figure 4 Constituent response for the composite models. (a) Yield surface representation of the "yield stress spectrum model". The solid dot represents the common initial stress state for all constituents and the arrow represents the loading direction. (b) Discretisation of a continuous normal distribution with a finite number of bins, the current plot shows 25 bins for clarity. (c) Yield surface representation of the "residual stress spectrum model". The dots represent the different residual stress states of the constituents and the arrow represents the loading direction. (d) Flat spectrum of a ranges of residual stresses, 25 constituents are presented in the current plot for clarity.

Therefore, the model is a simplification of the original model, which allowed multiaxial residual stress states $[34,35]$. Note that, in that case, the residual stress tensor is deviatoric. Of course, this simplified implementation lacks considerations of the effect of grain orientation and 3-D strain partitioning compared with the crystal plasticity model shown in the work of Hutchinson et al. [35]. However, it is still sufficient to capture the key ingredients of the residual stress hypothesis. The number of constituents is determined by the number of residual stress states $n_{c}$ and constituents have all the same volume fraction $V^{i}=1 / n_{c}$ and share the same yield stress $\sigma_{y 0}^{i}=\bar{\sigma}_{y 0}$. The maximum magnitude of the residual stress $\left(R S_{\max }\right)$ is defined as a fraction of $\bar{\sigma}_{y 0}$. The $R S_{\max }$ to $\sigma_{y 0}$ ratio is the only "unknown" variable in this model. In this way, the discretised distribution of constituents can be described by the flat spectrum shown in Figure $4 \mathrm{~d}$. The exact volume fractions of the constituents do not significantly affect the simulated flow behaviour of the bulk material as long as the residual stress spectrum is symmetrical and the macroscopic pre-stress averages to zero. Therefore, we do not seek to refine the flat spectrum with more sophisticated distributions. 


\subsubsection{Composite behaviour}

The composite is subjected to a uniaxial loading in the direction z. For a given increment of macroscopic strain $\Delta \bar{\varepsilon}_{z Z}$, the constituent strain increments $\Delta \varepsilon_{z Z}^{i}$ are calculated such that the following incremental strain partitioning condition is satisfied [17]:

$$
\beta=-\frac{\Delta \bar{\sigma}_{z z}-\Delta \sigma_{z z}^{i}}{\Delta \bar{\varepsilon}_{z z}-\Delta \varepsilon_{z z}^{i}}
$$

The value of $\beta$ can be varied to consider different strain partitioning conditions from iso-strain $(\beta=\infty)$ to isostress $(\beta=0)$. While this simple method is derived from previous works in dual-phase steels, it is a computationally efficient approach to treat the strain partitioning problem [65,66]. In addition to its computational advantage, the reason to use the $\beta$ factor approach in our work is two-fold. Firstly, it is the strain partitioning method used in the original work of Allain et al. [17] and we intend not to deviate to much from the original composite models other than the discretised 1-D simplifications shown in Figure 4. Secondly, the $\beta$ factor approach can treat the strain partitioning problem despite its simplicity, especially when the magnitude of $\beta$ is calibrated. Figure 5 shows the effect of $\beta$ on the magnitude of $\sigma_{\mu}$ and $\sigma_{s d}$ in the "yield stress spectrum model". It can be seen that $\sigma_{\mu}$ decreases as $\beta$ approaches to the iso-strain condition (Figure 5a) whereas $\sigma_{s d}$ increases (Figure $5 b$ ). Since we assume that the yield stress spectrum is symmetrical and the constituents are elastic, perfectly plastic, the mean of the yield stress spectrum should not deviate much from the experimental tensile strength. If this is not the case, the modelled UTS would be found far from the experimental value as the constituents closer to the mean account for most of the total volume fraction and contribute significantly to the modelled tensile curve. Therefore, $\beta$ is fixed as $\mathrm{E} / 4$ and it is the same for all constituents in the yield stress spectrum model. This is also the $\beta$ value used in the work of Allain et al. [17].
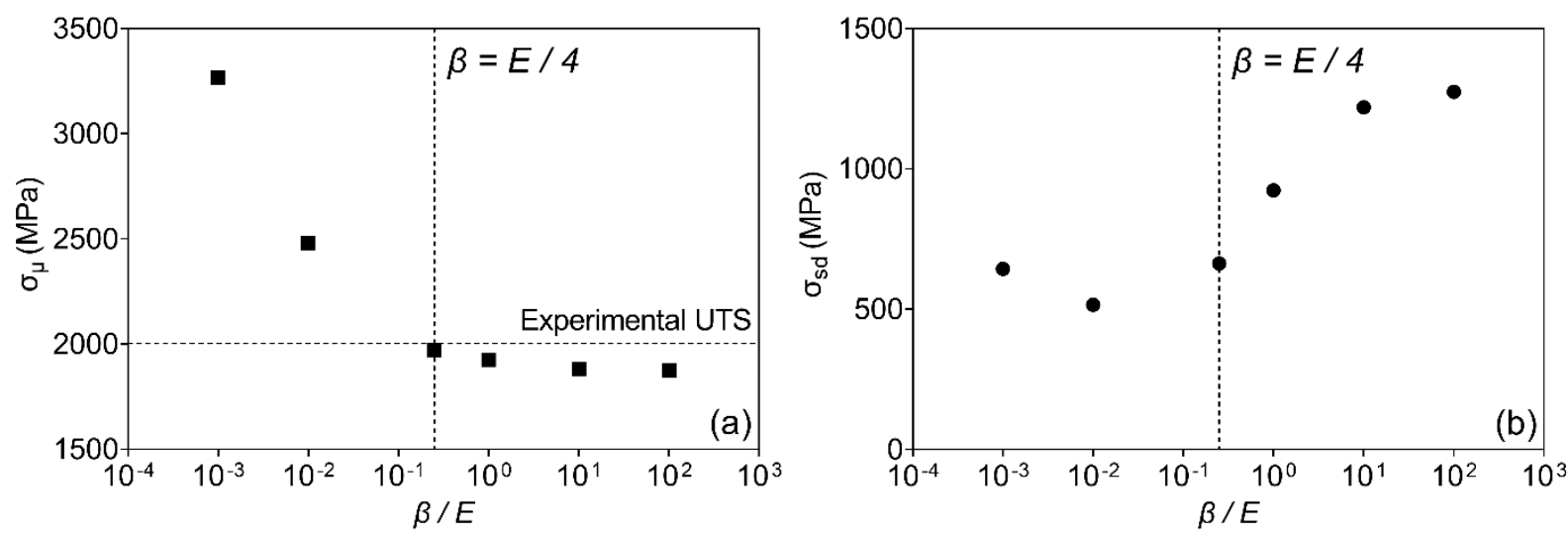

Figure 5 The effect of $\beta$ on the magnitudes of $\sigma_{\mu}$ and $\sigma_{s d}$. The parameters optimised to best describe the monotonic tensile behaviour of the as-quenched $\mathrm{Si}$ steel.

The increments of stress and strain in each constituent are related by the constitutive relation of the constituent, assuming that $\Delta \sigma_{x x}^{i}=\Delta \sigma_{y y}^{i}=0$. The macroscopic stress is calculated by averaging the stress in the constituents according to Eq. (2). Strain partitioning among constituents also ensures that the averaging condition for the strain, Eq. (1), is satisfied. The procedure is repeated at the next time step until the termination 
criteria is met. In practice, the constitutive equations for each constituent were integrated in time using the classic return-mapping algorithm for elastic, perfectly-plastic behaviour [67], accounting for pre-strain and pre-stress in the case of the "residual stress spectrum model". The condition of uniaxial stress state at constituent level was satisfied by iterating on the a-priori unknown transverse strains $\Delta \varepsilon_{x x}^{i}$ and $\Delta \varepsilon_{y y}^{i}$ using a Newton-Raphson scheme. The increments $\Delta \varepsilon_{z z}^{i}$ were calculated iteratively using another Newton-Raphson scheme at the composite level.

\subsubsection{Limitations with the current implementation}

It is worth noting the potential limitations with the current implementation. By assuming the constituents obey the $J_{2}$ yield criterion, it is implied that the constituents should yield at the same stress in both tension and compression. This is not necessarily true in the case of martensitic steels. Previous literature has demonstrated that martensitic steels display higher flow stress in compression and the difference between the compressive and tensile flow stresses decreases after tempering [68-71]. For a model that simulates the strain reversal behaviour of martensite, this strength differential (S-D) effect should be considered. However, due to the large aspect ratio of the tension-compression sample and issues with sample buckling, it was difficult to obtain compression and compression-tension test results with compressive strains larger than $1 \%$. A comprehensive test campaign on the impact of the S-D effect was thus not possible. Nevertheless, the omission of the S-D effect in the modelling framework does not affect significantly the modelled results in the two composite models as well as the predictive capability of the "integral composite model" proposed later (more details can be found in Appendix B).

The second limitation of the current modelling framework is the lack of strain hardening of the constituents. Our preliminary results showed that the inclusion of phenomenological strain hardening terms (either isotropic or kinematic) would reduce the variation in the yield stress spectrum and the residual stress spectrum and improve the agreement between the experimental and modelled results. The inclusion of strain hardening terms considering dislocation evolutions (e.g. dislocation cell formation [20,21,38,39,56,72] and dislocation-grain boundary interactions $[73,74]$ ) can also lead to extra kinematic hardening and a Bauschinger effect even if the composite models themselves cannot. However, the modelling parameters used in these hardening models are difficult to quantify physically and require additional calibration or fitting. Since it is our intention to compare the two existing composite models and avoid adding more "unknown" variables, the constituents in the current implementation are assumed to be elastic, perfectly plastic and no extra strain hardening is allowed.

\subsection{Comparison of composite models using their original hypotheses}

Figure 6 shows the experimental and modelled tension-compression curves using the "yield stress spectrum model" (Figure 6a, c and e). Using optimised yield stress distributions, the monotonic curves can be well reproduced by the model for all compositions. The model is also capable of producing a large Bauschinger effect since individual constituents have different stress states than the bulk which results in back stresses and 
kinematic hardening. However, significant discrepancies are observed when the same yield stress spectrum that works well during forward loading is used to simulate the tension-compression test. Regardless of the alloy composition, the model predicts a larger Bauschinger effect than the one experimentally measured.
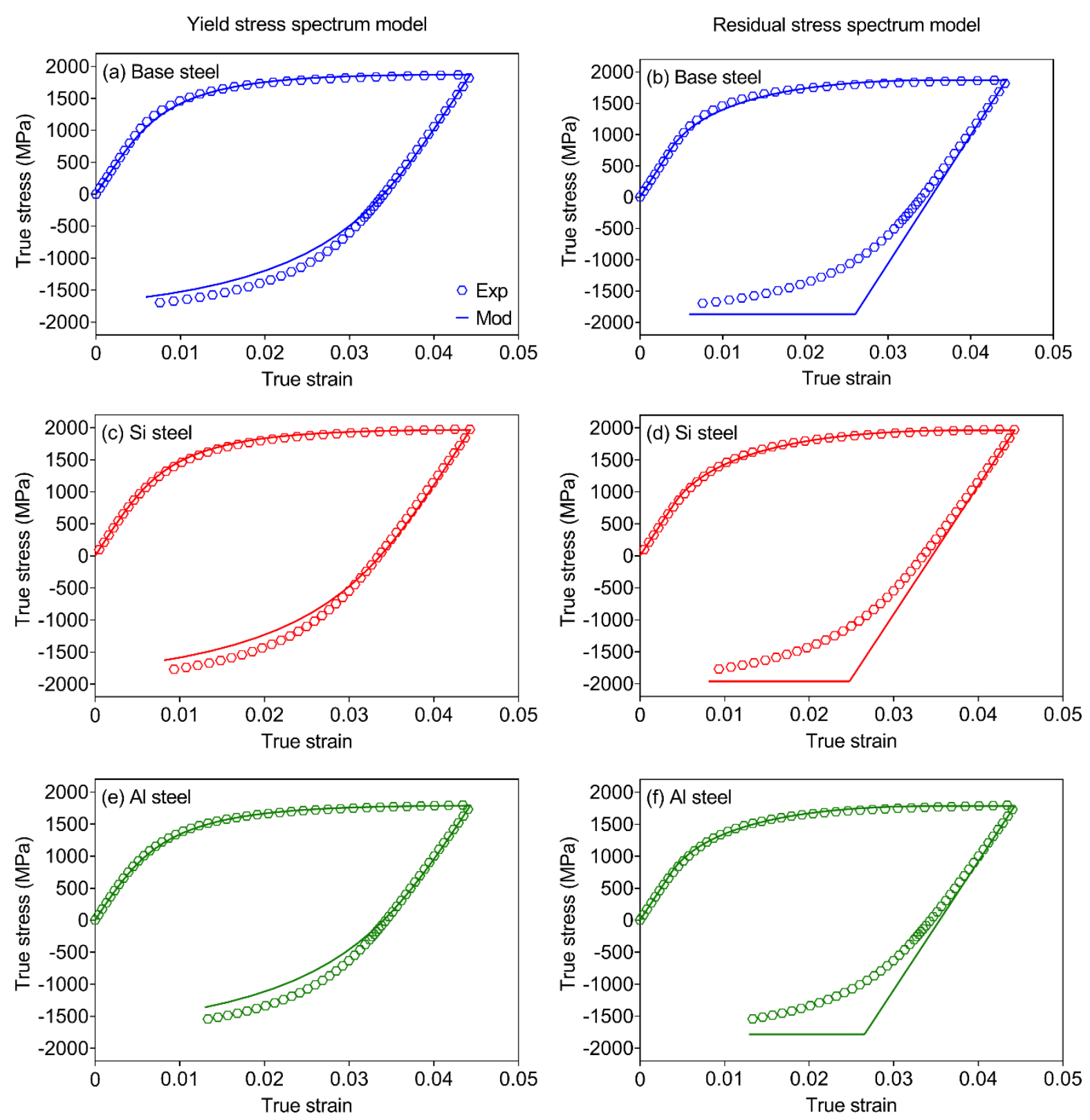

Figure 6 Experimental and modelled tension-compression curves for as-quenched samples using the "yield stress spectrum model" (a, c and e) and the "residual stress spectrum model" (b, $d$ and f).

In the case of the "residual stress model" (Figure 6b, $d$ and f), the common yield stress for the constituents $\left(\sigma_{y 0}^{i}\right)$ is set to be the same as the mean of the normal distribution obtained in the yield stress spectrum to allow a fair comparison between the models. The best agreement with the monotonic tension curves can be achieved when the maximum residual stress magnitude is set as $R S_{\max }=\sigma_{y 0}^{i} / \sqrt{3}$, which corresponds to $\sim 57 \%$ of the common yield stress of the material. While the monotonic tension curves can be well explained by the gradual yielding of constituents with pre-stresses, the model produces no Bauschinger effect during the tension- 
compression test simulations because the material behaves like a single element of elastic, perfectly-plastic materials during reverse loading. This is again likely to be caused by the lack of consideration of dislocation evolutions in the current implementation.

The discretised nature of the unified framework allows us to extract the strain and stress states of each constituent during straining. Figure $7 \mathrm{a}$ and $\mathrm{b}$ show the strain and stress states of each constituent along the loading direction at different macroscopic forward strains as a function of their initial yield stresses in the "yield stress spectrum model". In Figure 7a, it can be seen that the constituents with smaller initial yield stresses will yield first and bear larger strains whereas the constituents with larger initial yield stresses will still be elastic and bear a minimum strain. If we assume each constituent represents an aggregation of grains with a random texture, the strain partitioning phenomenon can lead to anisotropic elastic strains within the grains, which results in anisotropic shifts of the diffraction lines when the sample is probed by X-ray diffraction. Indeed, in-situ X-ray and neutron experiments do show that the diffraction lines of as-quenched martensite become asymmetric during deformation [35,36,38,39]. However, the predicted stress evolution shown in Figure $7 \mathrm{~b}$ does not respect another important feature found in the in-situ X-ray and neutron experiments which is the narrowing of diffraction lines during straining. In the basic assumptions of the "yield stress spectrum model", each constituent is elastic, perfectly plastic and its initial yield stress does not change as a function of straining. As a consequence, there is no mechanical homogenisation of the stress states in the material and straining should always lead to plastic incompatibilities between soft and hard constituents which can only result in diffraction line broadening. This is not consistent with experimental observations (Figure 3).
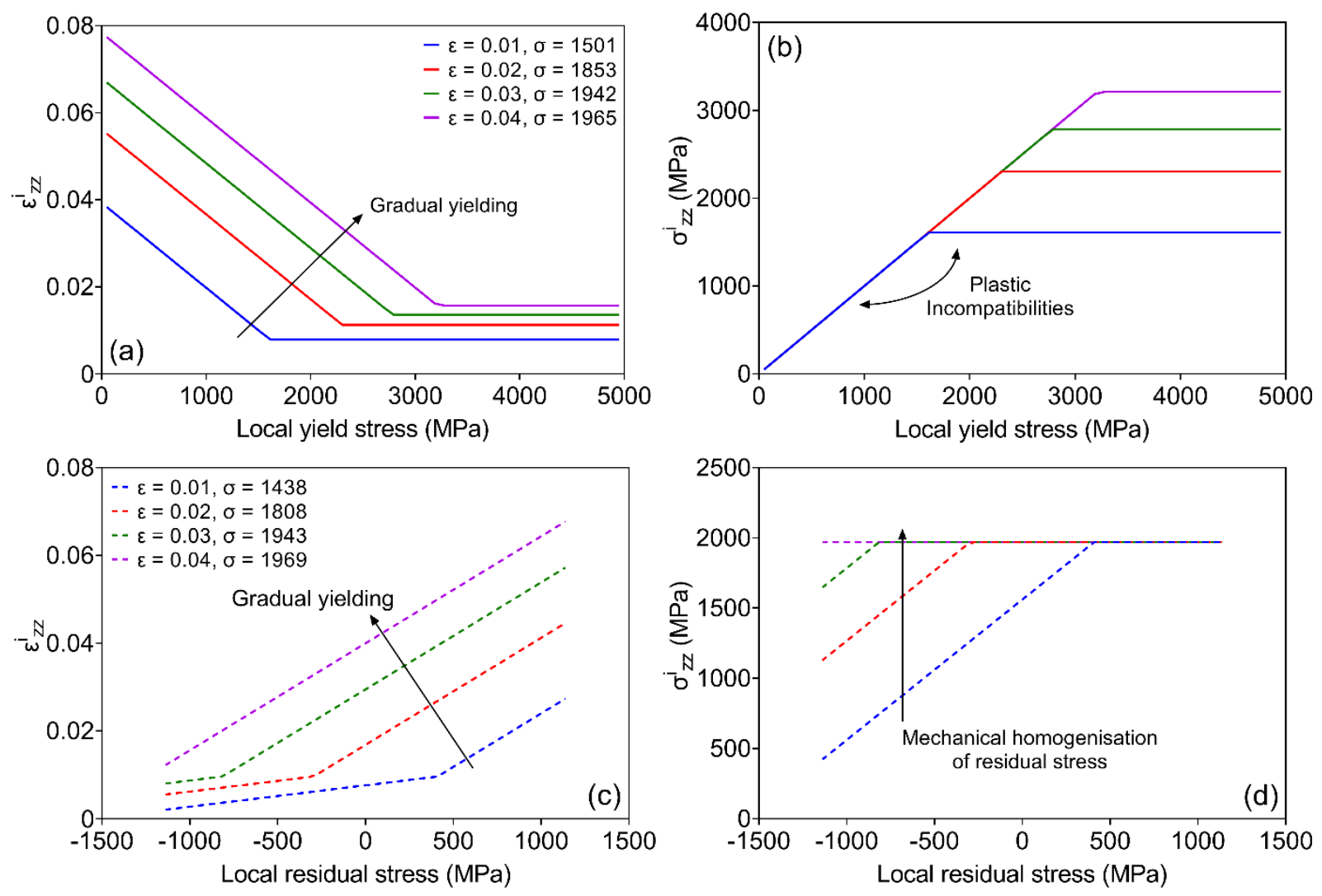
Figure 7 Strain and stress states of constituents as a function of their initial yield stress states (a and b) or their initial residual stress states (c and d) in a simulated tensile test. Different colours represent different macroscopic strain and stress levels. Simulated results from the as-quenched Si steel sample.

The disappearance of the Bauschinger effect in the case of the "residual stress spectrum model" is understood by the evolution of strain and stress states during straining. As shown in Figure 7c, constituents with positive pre-stresses yield first and bear larger strains while constituents with negative pre-stresses do not yield and bear smaller strains as a result of strain partitioning. The heterogeneity in strain at the constituent level leads to the same diffraction line asymmetry as discussed in the previous section. The stress states in individual constituents, on the other hand, becomes more homogeneous during straining since all constituents share the same initial yield stress (Figure 7d). When all constituents have their axial stress equal to the yield stress, the material is fully yielded and homogenised by plastic straining. This mechanical homogenisation process eliminates the plastic incompatibilities generated between early and late yield constituents. As a consequence, not only does the diffraction line get narrower as a result of residual stress relaxation, the material also loses its composite-like behaviour at large forward plastic strains and as a result a significant Bauschinger effect is not observed (Figure 6b, d and f). Therefore, the "residual stress spectrum model" alone cannot selfconsistently explain both the monotonic tension and the tension-compression flow behaviour of as-quenched martensite. Nevertheless, the residual stress hypothesis does provide a suitable explanation for diffraction line narrowing and should be considered in further model developments. In principle, both the yield stress spectrum and the residual stress spectrum should co-exist in as-quenched martensite as a result of the transformation sequence effect [27].

\subsection{An "integral composite model" incorporating both yield stress spectrum and residual stress spectrum hypotheses}

While both the "yield stress spectrum model" and the "residual stress spectrum model" are promising candidates in describing the flow behaviour of as-quenched martensite, they have limitations in explaining certain features: the "yield stress spectrum model" does not reflect the diffraction line narrowing phenomenon observed during straining of as-quenched martensite; the "residual stress spectrum model" does not result in a Bauschinger effect since the residual stresses are relaxed and the composite effect is eliminated after forward straining. It is, therefore, interesting to explore if the two models could be integrated into a new model that simultaneously considers the variation in local yield stresses and relaxation of residual stresses.

We first consider the possibility to include the relaxation of residual stresses into the "yield stress spectrum model". As discussed by Scott et al. [33] and Badinier [40], the variation in local yield stresses within martensite can come not only from the heterogeneous carbon contents in martensite crystals or lath size variations, but also from the residual stress states within different constituents. While the variation in intrinsic yield stresses should not change during deformation, the residual stresses can be relaxed during straining. Therefore, if the initial yield stress spectrum is affected by the existence of residual stresses, the spectrum 
should become narrower after deformation since the residual stresses are, to some extent, relaxed by the forward loading and exert less influence on the variation in yield stresses.

For the purpose of illustration, consider Figure 8. The black solid line in Figure 8a represents the initial apparent yield stress spectrum of the material which comes from the convolution of the intrinsic yield stress spectrum and the residual stress spectrum. Constituents that reside on the left-hand side of the distribution have smaller yield stresses compared to the mean of the distribution. Besides the lower intrinsic yield stresses, they are also likely to be affected by residual stresses that are aligned with the loading direction which result in the lower apparent yield stresses. As a result, these constituents will have smaller yield surfaces (dotted black line in Figure 8b) than the mean (solid black line). In contrast, constituents that are found on the right-hand side of the distribution are likely to be affected by higher intrinsic yield stresses and residual stresses that are opposite to the loading direction. These constituents can be represented by the larger yield surfaces shown as dashed black lines in Figure 8b. Upon straining, constituents with lower apparent yield stresses (i.e. left of the mean) will yield first and relax their residual stresses. Since they are affected by residual stresses that facilitate yielding in the forward direction, relaxation of these stresses will lead to an increase in the apparent yield stresses so their yield surfaces should expand (dotted red line in Figure 8b). On the other hand, when the forward strain is large enough to deform constituents with higher apparent yield stresses (i.e. right of the mean), the relaxation of residual stresses should lead to a loss of resistance to forward plasticity so the apparent yield stresses should decrease. Therefore, their yield surfaces should shrink (dashed red line in Figure 8b). As plasticity develops in all constituents, the influence of residual stresses become less and the width of the spectrum decreases, which can be represented by the red dashed spectrum in Figure 8a. 

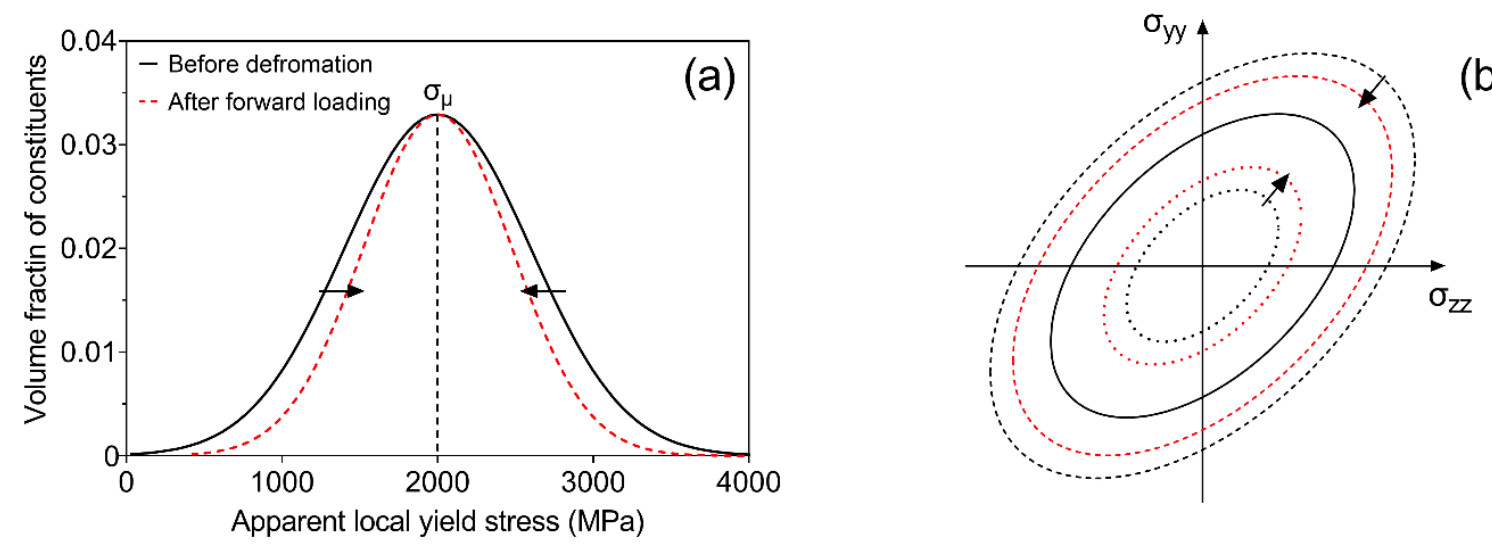

(b)
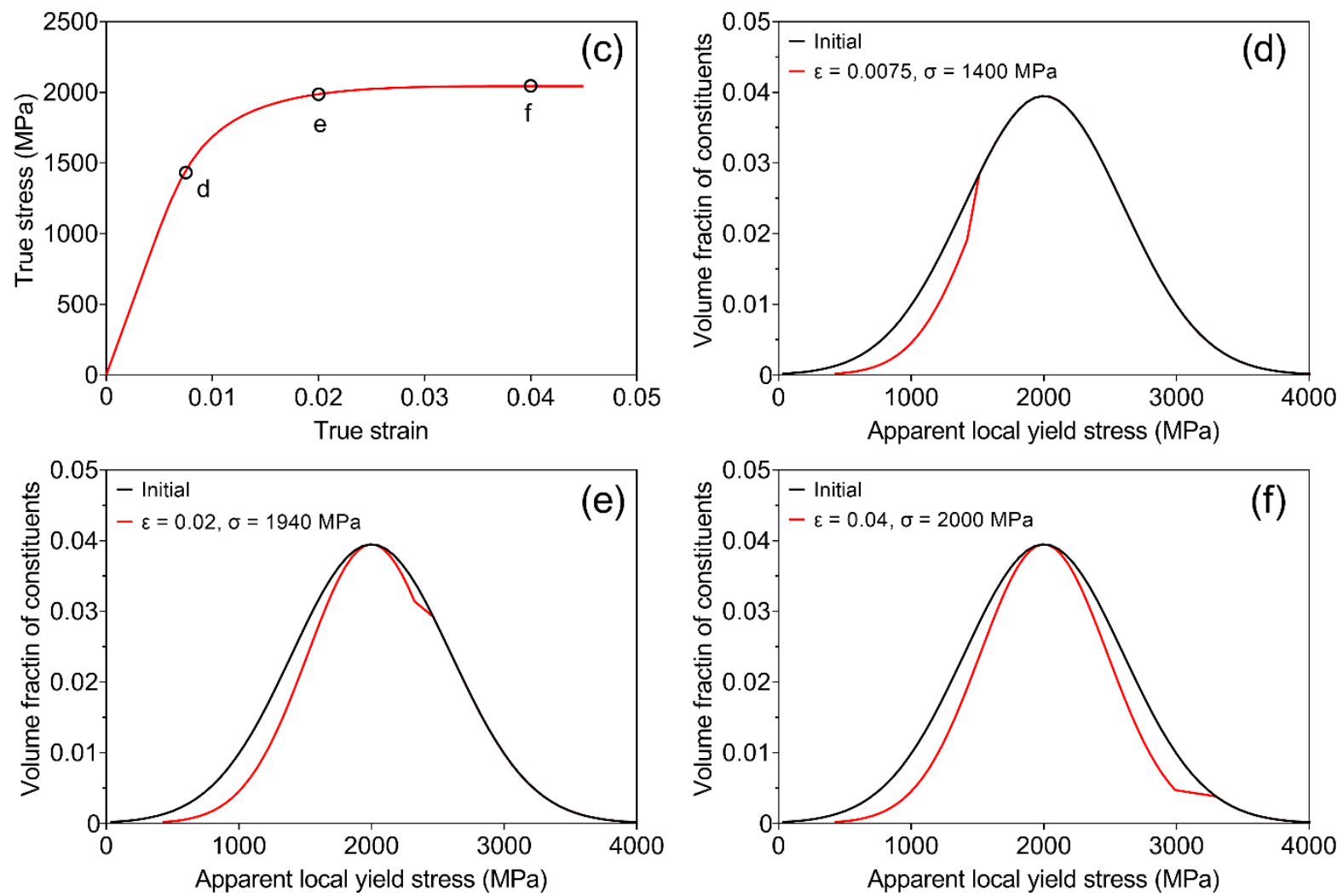

Figure 8 Constituent initialisation in the "integral composite model" and the modelled tensile test results. Modelling parameters are set as $\sigma_{\mu}=2000 \mathrm{MPa}, \sigma_{s d}=600 \mathrm{MPa}$ and $\alpha_{r}=0.2$. (a) Local yield stress spectra before and after forward loading. (b) Yield surfaces of constituents with lower (dotted lines) and higher (dashed lines) apparent local yield stress than the mean (solid black line). The red lines represent the size of the yield surface after relaxation of residual stresses. (c) Modelled tensile behaviour, black circles represent the strain and stress levels for the other plots. (d) - (f) Evolution of the apparent yield stress spectrum as a function of strain. The black curves represent the initial spectrum and the red curves represent the spectrum after relaxation of residual stresses.

In our implementation of this "integral composite model", the initialisation scheme for the "yield stress spectrum model" is used assuming a mean $\sigma_{\mu}$ and an initial spread $\sigma_{s d}^{0}$ (assuming a normal distribution similar to Eq. (4)). Each constituent is then assigned with an initial apparent yield stress $\sigma_{y 0}^{i}$. During straining, if the stress at the constituent level exceeds $\sigma_{y 0}^{i}$, the apparent yield stress is allowed to evolve to reflect a reduction in the residual stress contribution in the following way: 


$$
\sigma_{y r}^{i}=\sigma_{y 0}^{i}\left[1-\alpha_{r}\left(\frac{\sigma_{y 0}^{i}-\sigma_{\mu}}{\sigma_{y 0}^{i}}\right)\right]
$$

where $\sigma_{y r}^{i}$ is the apparent yield stress of the constituent after relaxation of residual stresses and $\alpha_{r}$ is the relaxation parameter ranging from 0 to 1 . In the first instance we assume this relaxation process occurs instantaneously when the constituent yields and no further hardening is allowed after the relaxation (i.e. constituents are still elastic, perfectly plastic). The $\left(\sigma_{y 0}^{i}-\sigma_{\mu}\right) / \sigma_{y 0}^{i}$ term allows Eq. (8) to locate the position of the constituent relative to the mean: if the constituent has a yield stress smaller than the mean, this term will be negative and vice versa. Together with the relaxation parameter $\alpha_{r}$, Eq. (8) is able to describe the magnitude of the change in the apparent yield stress for each constituent. Eq. (8) also regulates the maximum/minimum $\sigma_{y r}^{i}$ after residual stress relaxation: for a constituent with a smaller yield stress than the mean, $\sigma_{y r}^{i}=\sigma_{\mu}$ is the maximum value it can reach; for a constituent with a larger than the mean, $\sigma_{y r}^{i}=\sigma_{\mu}$ is the minimum value it can reach.

Figure $8 \mathrm{c}$ is an example of the modelled tensile curve assuming $\sigma_{\mu}=2000 \mathrm{MPa}, \sigma_{s d}^{0}=600 \mathrm{MPa}$, and $\alpha_{r}=0.2$. When the strain is low, only the constituents with lower apparent yield stresses are plastically deformed and the relaxation process leads to an asymmetric yield stress spectrum (Figure 8d). As plasticity develops, constituents with higher apparent yield stresses start to relax their residual stresses and the spectrum starts to become symmetrical again (Figure 8e-f). Figure $8 \mathrm{f}$ shows that if the constituents are heavily influenced by the convolution of large intrinsic yield stress and negative residual stresses, they may not yield even at large strains. However, these constituents only account for a small fraction of the total number constituents and will not affect greatly the overall flow behaviour. This statement can be supported by the slope of the modelled tensile curve after point $f$ where little strain hardening is observed. If the elastic constituents do contribute to the strain hardening of the bulk sample, the slope after point $f$ should still be large.

In this description, which includes a convolution of a yield strength spectrum and residual stress spectrum, $\sigma_{\mu}$, $\sigma_{s d}^{0}$ and $\alpha_{r}$ are the three "unknown" variables needed to fully describe the flow behaviour of martensite. While $\sigma_{\mu}$ and $\sigma_{s d}^{0}$ can be inferred from the "yield stress spectrum model", a key question with the "integral composite model" is the physical meaning of the relaxation parameter $\alpha_{r}$. Figure 9a shows the effect of $\alpha_{r}$ on the relaxed spectrum. If $\alpha_{r}=0$, there is no plastic relaxation of residual stresses during the forward straining and the apparent yield stress spectrum is maintained (i.e. equivalent to the "yield stress spectrum model"). If $\alpha_{r}=1$, the spectrum becomes a line located at $\sigma_{\mu}$, suggesting that all constituents share the same yield stress after complete relaxation (i.e. equivalent to the "residual stress spectrum model"). Therefore, $\alpha_{r}$ can be regarded as a parameter that describes the convolution of the "yield stress spectrum model" and the "residual stress spectrum model". The width of the yield stress spectrum after relaxation $\sigma_{s d}^{r}$ can then be calculated as the fraction of the width of the initial apparent yield stress spectrum:

$$
\sigma_{s d}^{r}=\sigma_{s d}^{0} \times\left(1-\alpha_{r}\right)
$$


As $\alpha_{r}$ increases, a larger fraction of the initial apparent yield stress spectrum will be influenced by the existence of residual stresses.

Since $\alpha_{r}$ is a parameter that describes the influence of residual stresses, it should evolve as a function of tempering as residual stresses can be relaxed by thermal treatments. Moreover, if the diffraction line narrowing as a function of strain is also a result of residual stress relaxation, the magnitude of this relaxation may be a suitable quantity to estimate $\alpha_{r}$. Figure 9b shows the evolution of the experimentally measured relaxation parameter from the interrupted X-ray diffraction experiments. In this case, the experimentally measured relaxation parameter is expressed as the magnitude of the microstrain reduction normalised by the microstrain before deformation (i.e. $\frac{\left\langle\varepsilon_{0}\right\rangle_{\text {Undeform }}-\left\langle\varepsilon_{0}\right\rangle_{\text {Deform }}}{\left\langle\varepsilon_{0}\right\rangle_{\text {Undeform }}}$ ). This normalised parameter represents the fraction of microstrain that can be relaxed by forward plasticity, which is the physical meaning of $\alpha_{r}$. It can be seen that the experimentally measured relaxation parameter remains relatively constant in the as-quenched and $300^{\circ} \mathrm{C}$ tempered conditions. When tempered at $400^{\circ} \mathrm{C}$, only the steels with $\mathrm{Si}$ and $\mathrm{Al}$ additions still show a considerable relaxation whereas the base steel shows no or negative relaxation.
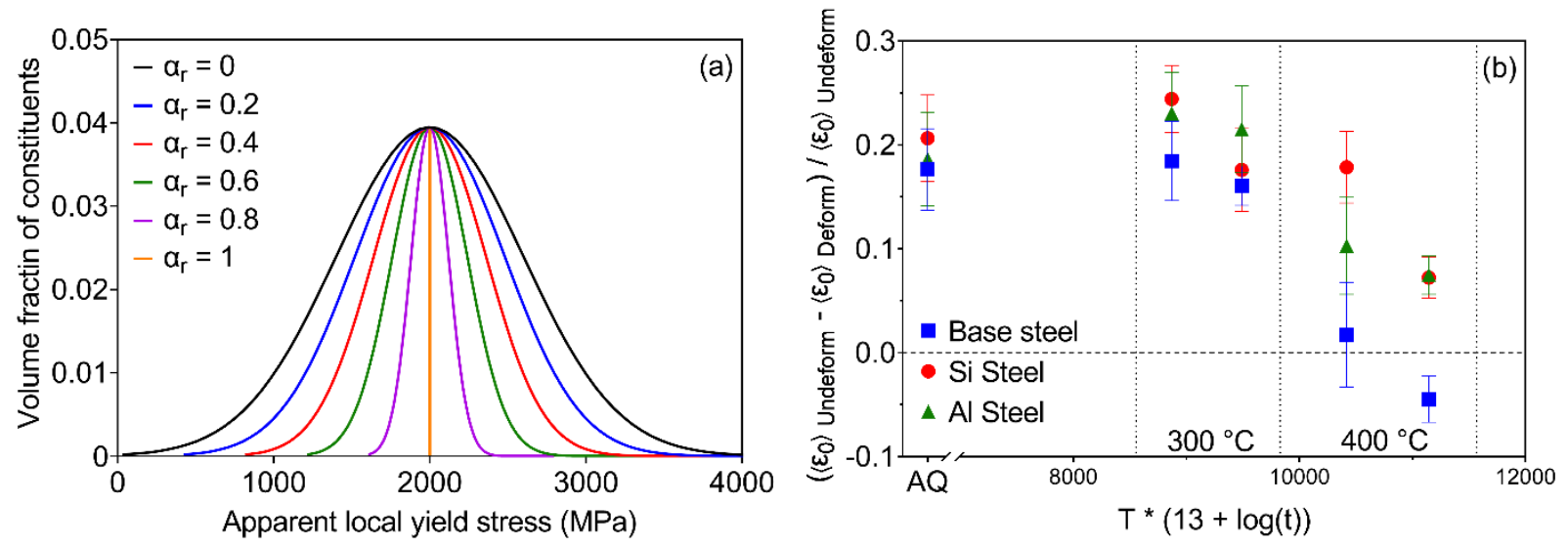

Figure 9 Effect and estimation of $\alpha_{r}$. (a) Effect of $\alpha_{r}$ on the evolution of the final yield stress spectrum. (b) Hollomon-Jaffe plot showing the evolution of the experimentally measured relaxation parameters from interrupted X-ray diffraction experiments. Error bars are calculated using the error propagation function considering the errors in the microstrain measurements shown in Figure 3. At each temperature, two tempering times are shown (i.e. 5 minutes and 1 hour).

Considering the contribution of dislocation based mechanisms and the scatter in experimental measurements, the estimated $\alpha_{r}$ values used in the model are shown in the first three rows of Table 2. It can be seen that most as-quenched and $300^{\circ} \mathrm{C}$ tempered samples share the same $\alpha_{r}$ value of 0.25 but the value for the base steel tempered at $300^{\circ} \mathrm{C}$ is reduced to 0.2 . This is to address the chemistry effect of $\mathrm{Si}$ and $\mathrm{Al}$ seen in the previous sections. In the case of $400^{\circ} \mathrm{C}$ tempered samples, $\alpha_{r}$ for the base steel is set to be zero since it shows limited (or even slightly negative) relaxation. For $\mathrm{Si}$ and $\mathrm{Al}$ steels tempered at $400^{\circ} \mathrm{C}$, the $\alpha_{r}$ values are obtained by slightly increasing the values in Figure $9 \mathrm{~b}$. 
To further reduce the degrees of freedom in the model, the mean of the initial apparent yield stress spectrum is set to be the experimentally measured UTS (Table 2). This constraint is similar to the one used in the original work of Hutchinson et al. and restricts the magnitude of the residual stress relaxation [34]. It also coincides with the assumption that the constituents are elastic, perfectly plastic (i.e. no strain hardening). The width of the initial apparent yield stress spectrum $\sigma_{s d}^{0}$ then becomes the single parameter that needs to be optimised in order to describe the flow behaviour of martensite.

Table 2 Magnitude of $\alpha_{r}, \sigma_{\mu}, \sigma_{s d}^{0}$ and $\sigma_{s d}^{r}$ used in the as-quenched and low temperature tempered conditions. $\alpha_{r}$ values are informed from diffraction line narrowing experiments and $\sigma_{\mu}$ values are measured from the UTS of the tensile curve. $\sigma_{s d}^{0}$ values are optimised to fit the tension-compression curve and $\sigma_{s d}^{r}$ values are calculated using Eq. (9).

\begin{tabular}{llccccc}
\hline Parameter & Steel grade & As-quenched & $300^{\circ} \mathrm{C} 5 \mathrm{~min}$ & $300^{\circ} \mathrm{C} 1 \mathrm{hr}$ & $400^{\circ} \mathrm{C} 5 \mathrm{~min}$ & $400^{\circ} \mathrm{C} 1 \mathrm{hr}$ \\
\hline \multirow{4}{*}{$\alpha_{r}$} & Base steel & 0.25 & 0.2 & 0.2 & 0 & 0 \\
& Si steel & 0.25 & 0.25 & 0.25 & 0.2 & 0.1 \\
& Al steel & 0.25 & 0.25 & 0.25 & 0.1 & 0.1 \\
\hline \multirow{3}{*}{$\sigma_{\mu}(\mathrm{MPa})$} & Base steel & 1900 & 1521 & 1487 & 1365 & 1271 \\
& Si steel & 2003 & 1734 & 1726 & 1619 & 1459 \\
& Al steel & 1815 & 1552 & 1482 & 1416 & 1262 \\
\hline \multirow{5}{*}{$\sigma_{s d}^{0}(\mathrm{MPa})$} & Base steel & 747 & 608 & 585 & 434 & 455 \\
& Si steel & 788 & 721 & 716 & 628 & 506 \\
& Al steel & 751 & 665 & 621 & 513 & 502 \\
\hline \multirow{2}{*}{$\sigma_{s d}^{r}(\mathrm{MPa})$} & Base steel & 560 & 486 & 468 & 434 & 455 \\
& Si steel & 591 & 541 & 537 & 502 & 516 \\
& Al steel & 563 & 499 & 466 & 462 & 452 \\
\hline
\end{tabular}

\subsection{Modelling results and discussions}

Figure $10 \mathrm{a}$ - e show the comparison between the experimental and modelled tension-compression curves for the as-quenched and low temperature tempered states of the base steel composition. The results for the Si and Al steels (which show similar levels of agreement) can be found in Figures A1 - A3 in the Appendix. The modelled curves are simulated using $\sigma_{s d}^{0}$ values that best reproduce the experimental curves. In the asquenched and $300^{\circ} \mathrm{C}$ tempered conditions, the modelled curves show good agreement with the experimental data and demonstrate better capabilities than the original composite models. The underestimation of the Bauschinger effect in the reverse direction for the as-quenched samples is eliminated since the relaxation of residual stresses is properly treated. Discrepancies between experimental and modelled curves start to appear when samples are tempered at $400^{\circ} \mathrm{C}$ as a result of accelerated microstructural homogenisation. This can be demonstrated by the underestimation around the elastic-plastic transitions during forward loading and the overestimation in the reverse direction, which is especially obvious in the samples tempered at $400^{\circ} \mathrm{C}$ for 1 hour (Figure 10e). It indicates that the integral composite model starts to become less capable in describing the flow behaviour of high temperature tempered samples. 
Another way to examine the capability of the "integral composite model" is to compare the correlation between the modelled $\sigma_{s d}^{r}$ and the experimentally measured UTS shown in Figure 10f. While most data points can be described by a master line regardless of alloy compositions, three points are located well away from the master line. These data points come from samples that are tempered at $400^{\circ} \mathrm{C}$ for 1 hour. It suggests that although we can obtain good agreement with experimental data for this tempering condition, the modelling parameters may not reflect the true variation in the intrinsic yield stress and could be caused by fitting uncertainties.
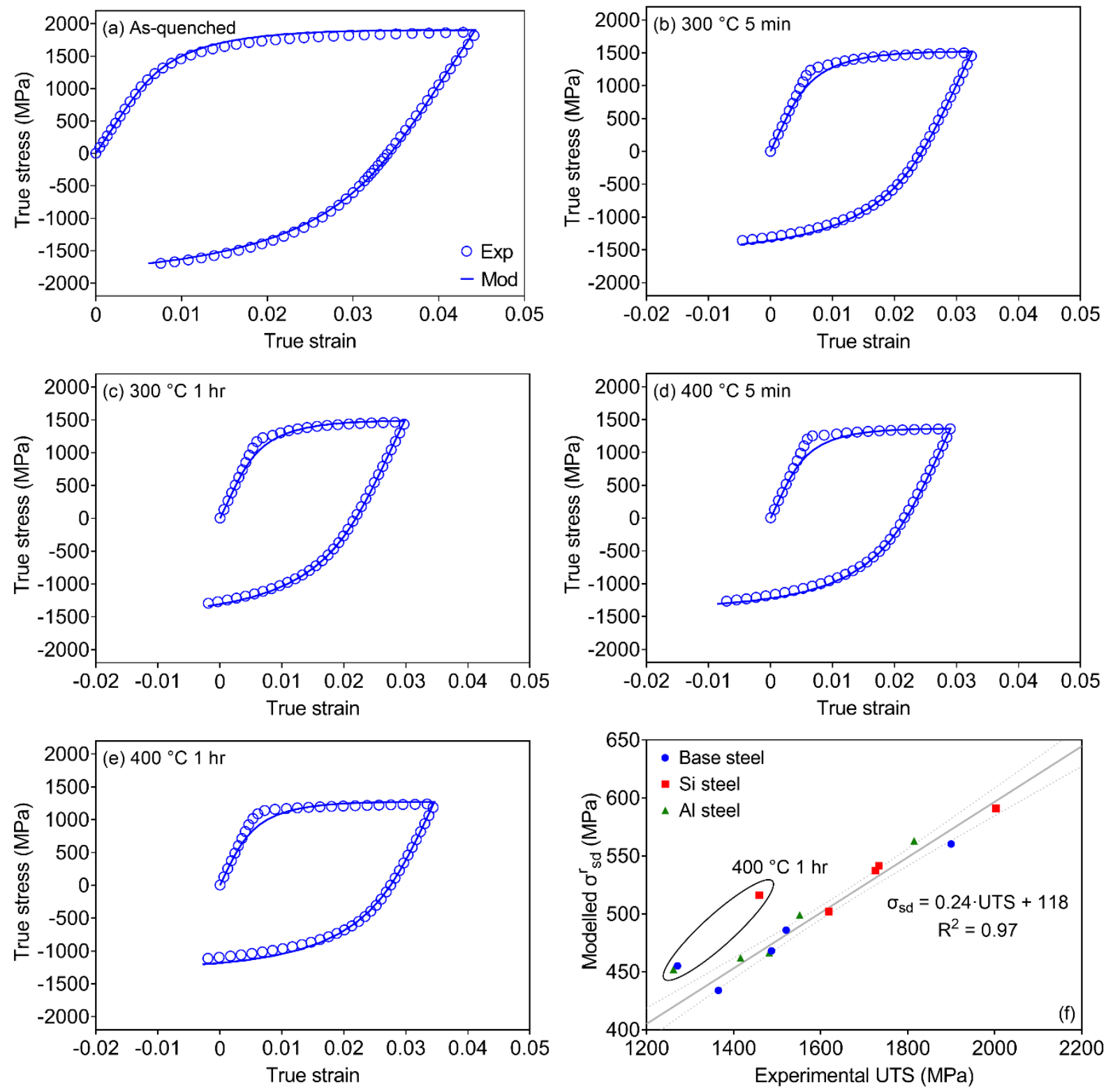

Figure 10 (a) - (e) Experimental and modelled tension-compression curves for the as-quenched and tempered samples. (f) Correlation between the modelled $\sigma_{s d}^{r}$ and the experimentally measured UTS. The solid line is fitted with a linear regression and the dashed curves represent the $95 \%$ confidence band of the fit.

Besides the uncertainties at high tempering temperatures, the existence of a master line (Figure 10f) that is chemistry insensitive suggests that it is possible to use the master line to predict the flow behaviour of asquenched and low temperature tempered martensite. Figure 11 shows the performance of the model in 
predicting the strain reversal behaviours of two as-quenched steels taken from the literature. In both cases, the mean of the spectrum $\sigma_{\mu}$ is set as the stress at the strain reversal. As both samples were tested to relatively large strains, the stress at the reversal will be close to the UTS. $\sigma_{s d}^{r}$ values are calculated using the equation shown in Figure 10f. Since the steels have similar carbon contents to the steels used in the current study, the same $\alpha_{r}$ of 0.25 is used and the initial width of the spectrum is calculated as $\sigma_{s d}^{0}=\sigma_{s d} /\left(1-\alpha_{r}\right)$ (i.e. the reciprocal of Eq. (9)). For steels with higher carbon contents, a larger $\alpha_{r}$ may be required since the developed residual stress could be larger as suggested by Hutchinson and co-workers [34,64]. It can be seen that the predicted curves have excellent agreement with the experimental results without any modification of the modelling parameters. This indicates that the "integral composite model" proposed here can usefully predict the flow behaviour of as-quenched and low temperature tempered martensite. The fact that the prediction for the shear reversal test is reasonably good suggests that the strength differential effect does not affect the validity of the "integral composite model".
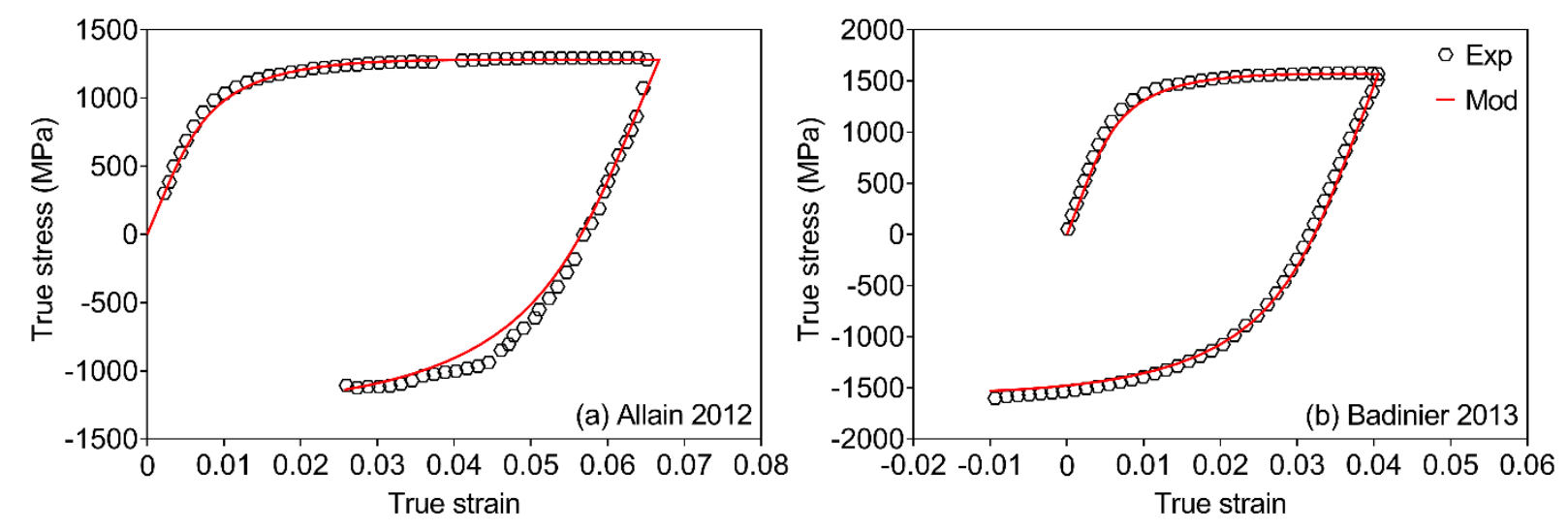

Figure 11 Experimental and modelled strain reversal behaviours of two steels found in the literature. (a) Fe-0.1C2.3Mn-0.3Si-0.8Cr (wt.\%) as-quenched steel modelled with $\sigma_{\mu}=1280 \mathrm{MPa}, \sigma_{s d}^{0}=566 \mathrm{MPa}$, and $\alpha_{r}=0.25$. Experimental results are from the shear reversal test. The Young's modulus is adjusted to 140 GPa to better describe the elastic behaviour. More explanation on this can be found in the work of Allain et al. [17]. (b) Fe-0.24C (wt.\%) as-quenched steel modelled with $\sigma_{\mu}=1568 \mathrm{MPa}, \sigma_{s d}^{0}=659 \mathrm{MPa}$, and $\alpha_{r}=0.25$. Experimental results are from the uniaxial tensions-compression test $[40]$.

\section{Conclusion}

A systematic study of the strain hardening behaviour during tensile and reverse loading of as-quenched and low temperature tempered $\left(300^{\circ} \mathrm{C}\right.$ and $\left.400^{\circ} \mathrm{C}\right)$ martensite has been conducted. Both as-quenched and tempered martensite show large strain hardening behaviour (i.e. greater than the E/50 limit), pronounced and sustained Bauschinger effect and diffraction peak narrowing. The diffraction peak narrowing phenomenon persists in samples tempered at $300^{\circ} \mathrm{C}$ and disappears gradually when the tempering temperature is raised to $400^{\circ} \mathrm{C}$.

While the "yield stress spectrum model" is able to describe both the monotonic tension and the tensionscompression flow behaviour of as-quenched martensite, it fails to address the diffraction line narrowing phenomenon observed in in-situ Neutron and X-ray diffraction. By contrast, the "residual stress spectrum 
model" can describe the monotonic tension curve and provide natural explanations to the diffraction line narrowing problem but it cannot reproduce a large and sustained Bauschinger effect. These observations are well described by an "integral composite" model synthesising the contribution of both residual stress relaxation and incompatibility stresses. This approach also allows an empirical correlation to be found which is capable of predicting the flow behaviour of as-quenched martensite found in the literature.

\section{Acknowledgments}

The authors would like to thank the support of ArcelorMittal and the Australian Research Council through the Linkage Grant Scheme (LP150100756). YXW and LYW gratefully acknowledges the award of the Australian Government Research Training Program (RTP). The authors would also like to express thanks for the use of equipment within the Monash X-Ray Platform (MXP).

\section{References}

[1] G. Krauss, Martensite in steel: strength and structure, Mater. Sci. Eng. A. 273-275 (1999) 40-57. doi:10.1016/S0921-5093(99)00288-9.

[2] G.R. Speich, H. Warlimont, Yield Strength and transformation substructure of low-carbon martensite, Iron Steel Inst. 206 (1968) 385-392.

[3] L.-Å. Norström, On the Yield Strength of Quenched Low-Carbon Lath Martensite, Scand. J. Metall. 5 (1976) 159-165.

[4] B. Hutchinson, J. Hagström, O. Karlsson, D. Lindell, M. Tornberg, F. Lindberg, M. Thuvander, Microstructures and hardness of as-quenched martensites (0.1-0.5\%C), Acta Mater. 59 (2011) 5845 5858. doi:10.1016/j.actamat.2011.05.061.

[5] M.J. Roberts, Effect of transformation substructure on the strength and toughness of Fe-Mn alloys, Metall. Trans. 1 (1970) 3287-3294. doi:10.1007/BF03037855.

[6] S. Morito, H. Yoshida, T. Maki, X. Huang, Effect of block size on the strength of lath martensite in low carbon steels, Mater. Sci. Eng. A. 438-440 (2006) 237-240. doi:10.1016/j.msea.2005.12.048.

[7] G. Krauss, A.R. Marder, The morphology of martensite in iron alloys, Metall. Trans. 2 (1971) 23432357. doi:10.1007/BF02814873.

[8] T. Swarr, G. Krauss, The effect of structure on the deformation of as-quenched and tempered martensite in an Fe-0.2 pet C alloy, Metall. Trans. A. 7 (1976) 41-48. doi:10.1007/BF02644037.

[9] S. Morito, J. Nishikawa, T. Maki, Dislocation Density within Lath Martensite in Fe-C and Fe-Ni Alloys, ISIJ Int. 43 (2003) 1475-1477. doi:10.2355/isijinternational.43.1475.

[10] M. Kehoe, P.M. Kelly, The role of carbon in the strenght of ferrous martensite, Scr. Metall. 4 (1970) 473-476. doi:10.1016/0036-9748(70)90088-8.

[11] C.C. Tasan, M. Diehl, D. Yan, M. Bechtold, F. Roters, L. Schemmann, C. Zheng, N. Peranio, D. Ponge, M. Koyama, K. Tsuzaki, D. Raabe, An Overview of Dual-Phase Steels: Advances in MicrostructureOriented Processing and Micromechanically Guided Design, Annu. Rev. Mater. Res. 45 (2014) 150504161757009. doi:10.1146/annurev-matsci-070214-021103. 
[12] P.J. Jacques, Q. Furnémont, F. Lani, T. Pardoen, Multiscale mechanics of TRIP-assisted multiphase steels: I. Characterization and mechanical testing, Acta Mater. 55 (2007) 3681-3693. doi:10.1016/j.actamat.2007.02.029.

[13] A. Arlazarov, O. Bouaziz, J.P. Masse, F. Kegel, Characterization and modeling of mechanical behavior of quenching and partitioning steels, Mater. Sci. Eng. A. 620 (2014) 293-300. doi:10.1016/j.msea.2014.10.034.

[14] H. Muir, B.L. Averbach, M. Cohen, The elastic limit and yield behavior of hardened steels, Trans. Am. Soc. Met. 47 (1955) 380-407.

[15] M.A. Zaccone, G. Krauss, Elastic limits and microplastic response in ultrahigh strength carbon steels, Metall. Trans. A. 20 (1989) 188-191. doi:10.1007/BF02647507.

[16] M.A. Zaccone, G. Krauss, Elastic limit and microplastic response of hardened steels, Metall. Trans. A. 24 (1993) 2263-2277. doi:10.1007/BF02648600.

[17] S. Allain, O. Bouaziz, M. Takahashi, Toward a New Interpretation of the Mechanical Behaviour of Asquenched Low Alloyed Martensitic Steels, ISIJ Int. 52 (2012) 717-722. doi:10.2355/isijinternational.52.717.

[18] U.F. Kocks, H. Mecking, Physics and phenomenology of strain hardening: The FCC case, Prog. Mater. Sci. 48 (2003) 171-273. doi:10.1016/S0079-6425(02)00003-8.

[19] A.J. Mcevily, R.C. Ku, T.L. Johnston, The Source of Martensite Strength, Trans. Metall. Soc. AIME. 236 (1962) 108-114.

[20] S. Takaki, K.-L. Ngo-Huynh, N. Nakada, T. Tsuchiyama, Strengthening Mechanism in Ultra Low Carbon Martensitic Steel, ISIJ Int. 52 (2012) 710-716. doi:10.2355/isijinternational.52.710.

[21] D. Akama, T. Tsuchiyama, S. Takaki, Change in Dislocation Characteristics with Cold Working in Ultralow-carbon Martensitic Steel, ISIJ Int. $56 \quad$ (2016) 1675-1680. doi:10.2355/isijinternational.ISIJINT-2016-140.

[22] C.L. Magee, H.W. Paxton, The Microplastic Response of Partially Transformed Fe-31Ni, Trans. Metall. Soc. AIME. 242 (1968) 1741-1749.

[23] L. Morsdorf, O. Jeannin, D. Barbier, M. Mitsuhara, D. Raabe, C.C. Tasan, Multiple mechanisms of lath martensite plasticity, Acta Mater. 121 (2016) 202-214. doi:10.1016/j.actamat.2016.09.006.

[24] S. Morito, K. Oh-ishi, K. Hono, T. Ohba, Carbon Enrichment in Retained Austenite Films in Low Carbon Lath Martensite Steel, ISIJ Int. 51 (2011) 1200-1202. doi:10.2355/isijinternational.51.1200.

[25] F. Maresca, V.G. Kouznetsova, M.G.D. Geers, On the role of interlath retained austenite in the deformation of lath martensite, Model. Simul. Mater. Sci. Eng. 22 (2014) 045011. doi:10.1088/09650393/22/4/045011.

[26] C. Du, J.P.M. Hoefnagels, R. Vaes, M.G.D. Geers, Plasticity of lath martensite by sliding of substructure boundaries, Scr. Mater. 120 (2016) 37-40. doi:10.1016/j.scriptamat.2016.04.006.

[27] L. Morsdorf, C.C. Tasan, D. Ponge, D. Raabe, 3D structural and atomic-scale analysis of lath martensite: Effect of the transformation sequence, Acta Mater. 95 (2015) 366-377. doi:10.1016/j.actamat.2015.05.023. 
[28] G. Masing, Zur Heyn'schen Theorie der Verfestigung der Metalle durch verborgen elastische Spannungen, in: S.B. Heidelberg (Ed.), Wissenschaftliche Veröffentlichungen Aus Dem SiemensKonzern, Springer Berlin Heidelberg, Berlin, Heidelberg, 1923: pp. 231-239.

[29] R.J. Asaro, Elastic-Plastic Memory and Kinematic Type Hardening, Acta Metall. 23 (1975) 1255-1265.

[30] G. Badinier, C.W. Sinclair, X. Sauvage, X. Wang, V. Bylik, M. Gouné, F. Danoix, Microstructural heterogeneity and its relationship to the strength of martensite, Mater. Sci. Eng. A. 638 (2015) 329339. doi:10.1016/j.msea.2015.04.088.

[31] B.B. He, M.X. Huang, Revealing the Intrinsic Nanohardness of Lath Martensite in Low Carbon Steel, Metall. Mater. Trans. A Phys. Metall. Mater. Sci. 46 (2014) 688-694. doi:10.1007/s11661-014-26817.

[32] L. Zhang, T. Ohmura, K. Tsuzaki, Application of Nanoindentation Technique in Martensitic Structures, in: Nanoindentation Mater. Sci., InTech, Rijeka, 2012: pp. 109-130. doi:10.5772/48327.

[33] C.P. Scott, B. Shalchi Amirkhiz, I. Pushkareva, F. Fazeli, S.Y.P. Allain, H. Azizi, New insights into martensite strength and the damage behaviour of dual phase steels, Acta Mater. 159 (2018) 112-122. doi:10.1016/j.actamat.2018.08.010.

[34] B. Hutchinson, D. Lindell, M. Barnett, Yielding Behaviour of Martensite in Steel, ISIJ Int. 55 (2015) 1114-1122. doi:10.2355/isijinternational.55.1114.

[35] B. Hutchinson, P. Bate, D. Lindell, A. Malik, M. Barnett, P. Lynch, Plastic yielding in lath martensites - An alternative viewpoint, Acta Mater. 152 (2018) 239-247. doi:10.1016/j.actamat.2018.04.039.

[36] S. Morooka, Y. Tomota, T. Kamiyama, Heterogeneous Deformation Behavior Studied by in Situ Neutron Diffraction during Tensile Deformation for Ferrite, Martensite and Pearlite Steels, ISIJ Int. 48 (2008) 525-530. doi:10.2355/isijinternational.48.525.

[37] S. Harjo, T. Kawasaki, S. Morooka, Changes of Dislocation Density and Dislocation Arrangement during Tensile Deformation in Lath Martensitic Steels, Adv. Exp. Mech. 2 (2017) 112-117. doi:10.11395/aem.2.0_112.

[38] T. Ungár, S. Harjo, T. Kawasaki, Y. Tomota, G. Ribárik, Z.M. Shi, Composite Behavior of Lath Martensite Steels Induced by Plastic Strain, a New Paradigm for the Elastic-Plastic Response of Martensitic Steels, Metall. Mater. Trans. A. 48 (2017) 159-167. doi:10.1007/s11661-016-3845-4.

[39] S. Harjo, T. Kawasaki, Y. Tomota, W. Gong, K. Aizawa, G. Tichy, Z.G. Shi, T. Ungár, Work Hardening, Dislocation Structure, and Load Partitioning in Lath Martensite Determined by In Situ Neutron Diffraction Line Profile Analysis, Metall. Mater. Trans. A. 48 (2017) 4080-4092. doi:10.1007/s11661-017-4172-0.

[40] G. Badinier, Effect of Carbon Segregation and Carbide Precipitation on the Mechanical Response of Martensite, The University of British Columbia, 2013.

[41] J.G. Speer, Phase transformations in quenched and partitioned steels, in: E. Pereloma, D.V.B.T.-P.T. in S. Edmonds (Eds.), Phase Transform. Steels, Elsevier, 2012: pp. 247-270. doi:10.1533/9780857096111.2.247.

[42] G.R. Speich, Tempering of Low-Carbon Martensite, Trans. Metall. Soc. AIME. 245 (1969) 2553-2564. 
[43] G.R. Speich, W.C. Leslie, Tempering of steel, Metall. Trans. 3 (1972) 1043-1054. doi:10.1007/BF02642436.

[44] G. Krauss, Deformation and fracture in martensitic carbon steels tempered at low temperatures, Metall. Mater. Trans. B. 32 (2001) 205-221. doi:10.1007/s11663-001-0044-4.

[45] G. Krauss, Tempering of Lath Martensite in Low and Medium Carbon Steels: Assessment and Challenges, Steel Res. Int. 87 (2017) 1700038. doi:10.1002/srin.201700038.

[46] L. Malik, J.A. Lund, A study of strengthening mechanisms in tempered martensite from a medium carbon steel, Metall. Trans. 3 (1972) 1403-1406. doi:10.1007/BF02643024.

[47] L.R. Cupertino Malheiros, E.A. Pachon Rodriguez, A. Arlazarov, Mechanical behavior of tempered martensite: Characterization and modeling, Mater. Sci. Eng. A. 706 (2017) 38-47. doi:10.1016/j.msea.2017.08.089.

[48] E.I. Galindo-Nava, P.E.J. Rivera-Diaz-del-Castillo, A model for the microstructure behaviour and strength evolution in lath martensite, Acta Mater. 98 (2015) 81-93. doi:10.1016/j.actamat.2015.07.018.

[49] B. Kim, E. Boucard, T. Sourmail, D. San Martín, N. Gey, P.E.J. Rivera-Díaz-del-Castillo, The influence of silicon in tempered martensite: Understanding the microstructure-properties relationship in 0.50.6wt.\% C steels, Acta Mater. 68 (2014) 169-178. doi:10.1016/j.actamat.2014.01.039.

[50] S.F. Corbin, D.S. Wilkinson, J.D. Embury, The Bauschinger effect in a particulate reinforced Al alloy, Mater. Sci. Eng. A. 207 (1996) 1-11. doi:10.1016/0921-5093(95)10028-8.

[51] J. da Costa Teixeira, L. Bourgeois, C.W. Sinclair, C.R. Hutchinson, The effect of shear-resistant, plateshaped precipitates on the work hardening of Al alloys: Towards a prediction of the strength-elongation correlation, Acta Mater. 57 (2009) 6075-6089. doi:10.1016/j.actamat.2009.08.034.

[52] G. Badinier, C.W. Sinclair, S. Allain, O. Bouaziz, The Bauschinger effect in drawn and annealed nanocomposite Cu-Nb wires, Mater. Sci. Eng. A. 597 (2014) 10-19. doi:10.1016/j.msea.2013.12.031.

[53] D. Balzar, Voigt-function model in diffraction line-broadening analysis, in: R.L. Snyder, H.J. Bunge, J. Fiala (Eds.), Microstruct. Anal. from Diffr., International Union of Crystallography, 1999. doi:10.1.1.30.7311.

[54] S. Kennett, Strengthening and Toughnening Mechanisms in Low-C Microalloyed Steel as Influenced by Austenite Conditioning, Colorado School of Mines, 2014.

[55] F. HajyAkbary, J. Sietsma, A.J. Böttger, M.J. Santofimia, An improved X-ray diffraction analysis method to characterize dislocation density in lath martensitic structures, Mater. Sci. Eng. A. 639 (2015) 208-218. doi:10.1016/j.msea.2015.05.003.

[56] É. Ódor, B. Jóni, G. Ribárik, N.Q. Chinh, T. Ungár, P.J. Szabó, Deformation Induced Soft and Hard Lath Packets Enhance Ductility in Martensitic Steels, Crystals. 10 (2020) 373. doi:10.3390/cryst10050373.

[57] G. Krauss, Steels: processing, structure, and performance, ASM International, 2015.

[58] M.D. Richards, C.J. Van Tyne, D.K. Matlock, The influence of dynamic strain aging on resistance to strain reversal as assessed through the Bauschinger effect, Mater. Sci. Eng. A. 528 (2011) 7926-7932. doi:10.1016/j.msea.2011.07.015. 
[59] L. Zhonghua, G. Haicheng, Bauschinger effect and residual phase stresses in two ductile-phase steels: Part I. The influence of phase stresses on the Bauschinger effect, Metall. Trans. A. 21 (1990) 717-724. doi:10.1007/BF02671942.

[60] K. Han, C.J. Van Tyne, B.S. Levy, Bauschinger effect response of automotive sheet steels, SAE Trans. J. Mater. Manuf. 114 (2005) 27-33.

[61] G.D. Moan, J.D. Embury, A study of the bauschinger effect in Al-Cu alloys, Acta Metall. 27 (1979) 903-914. doi:10.1016/0001-6160(79)90125-1.

[62] J.L. Chaboche, A review of some plasticity and viscoplasticity constitutive theories, Int. J. Plast. 24 (2008) 1642-1693. doi:10.1016/j.ijplas.2008.03.009.

[63] J.H. Hollomon, L.D. Jaffe, Time-temperature relations in tempering steel, Trans. Metall. Soc. AIME. (1945) 223-249.

[64] B. Hutchinson, J. Brask, An Investigation of Short Range Residual Stress Fields in Ferrous Lath Martensite, Metall. Mater. Trans. A. 50 (2019) 5581-5584. doi:10.1007/s11661-019-05501-9.

[65] B. Karlsson, G. Lindén, Plastic Deformation of Ferrite -- Pearlite Structures in Steel, Mater. Sci. Eng. 17 (1975) 209-219. doi:10.1016/0025-5416(75)90232-3.

[66] N.C. Goel, S. Sangal, K. Tangri, A theoretical model for the flow behavior of commercial dual-phase steels containing metastable retained austenite: Part I. derivation of flow curve equations, Metall. Trans. A. 16 (1985) 2013-2021. doi:10.1007/BF02662402.

[67] I. Doghri, Elasto-plasticity, in: Mech. Deform. Solids, Springer Berlin Heidelberg, Berlin, Heidelberg, 2000: pp. 301-327. doi:10.1007/978-3-662-04168-0_12.

[68] W.C. Leslie, R.J. Sober, The strength of ferrite and of martensite as functions of composition, temperature and strain rate, Trans. ASM. 60 (1967) 459-484.

[69] J.P. Hirth, M. Cohen, On the strength-differential phenomenon in hardened steel, Metall. Trans. 1 (1970) 3-8. doi:10.1007/BF02819235.

[70] G.C. Rauch, W.C. Leslie, The extent and nature of the strength differential effect in steel, Metall. Trans. 3 (1972) 373-385. doi:10.1007/BF02642041.

[71] R. Chait, Factors influencing the strength differential of high strength steels, Metall. Trans. 3 (1972) 369-375. doi:10.1007/BF02642040.

[72] E.F. Rauch, J.J. Gracio, F. Barlat, Work-hardening model for polycrystalline metals under strain reversal at large strains, Acta Mater. 55 (2007) 2939-2948. doi:10.1016/j.actamat.2007.01.003.

[73] C.W. Sinclair, W.J. Poole, Y. Bréchet, A model for the grain size dependent work hardening of copper, Scr. Mater. 55 (2006) 739-742. doi:10.1016/j.scriptamat.2006.05.018.

[74] S. Cobo, O. Bouaziz, Investigations and Modelling of the Work Hardening of As-Quenched Martensite, in: New Dev. Metall. Appl. High Strength Steels, Buenos Aires 2008 - Proc. Int. Conf. New Dev. Metall. Appl. High Strength Steels, 2008: pp. 909-918.

[75] P.N. Thielen, M.E. Fine, Cyclic strength differential effect in 4140 steel, Scr. Metall. 9 (1975) 383386. doi:10.1016/0036-9748(75)90168-4.

[76] W.A. Spitzig, O. Richmond, The effect of pressure on the flow stress of metals, Acta Metall. 32 (1984) 
457-463. doi:10.1016/0001-6160(84)90119-6.

[77] D.C. Drucker, W. Prager, Soil mechanics and plastic analysis or limit design, Q. Appl. Math. 10 (1952) 157-165. doi:10.1090/qam/48291.

\section{Appendix A}
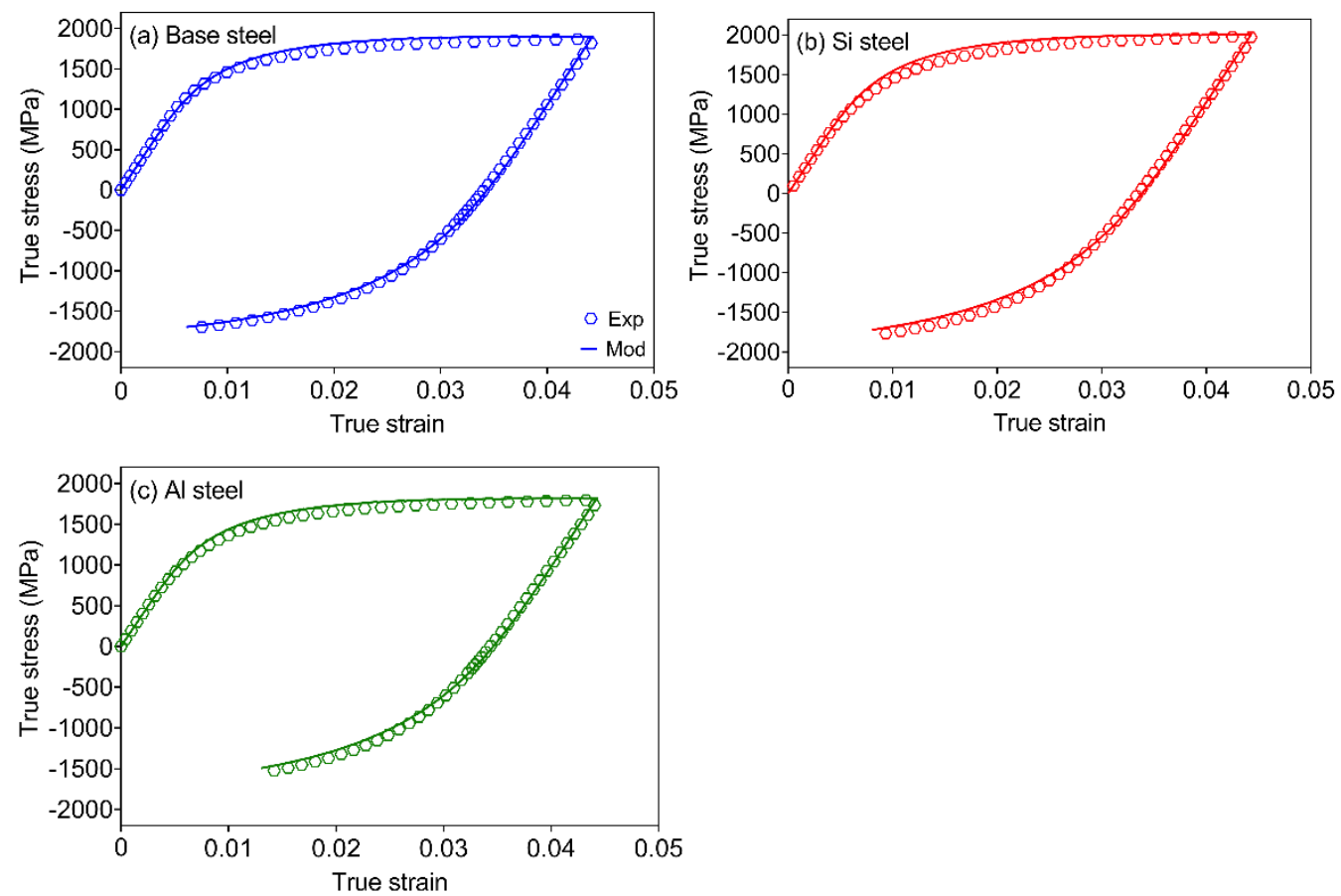

Figure A1 Experimental and modelled tension-compression curves for the as-quenched samples. 

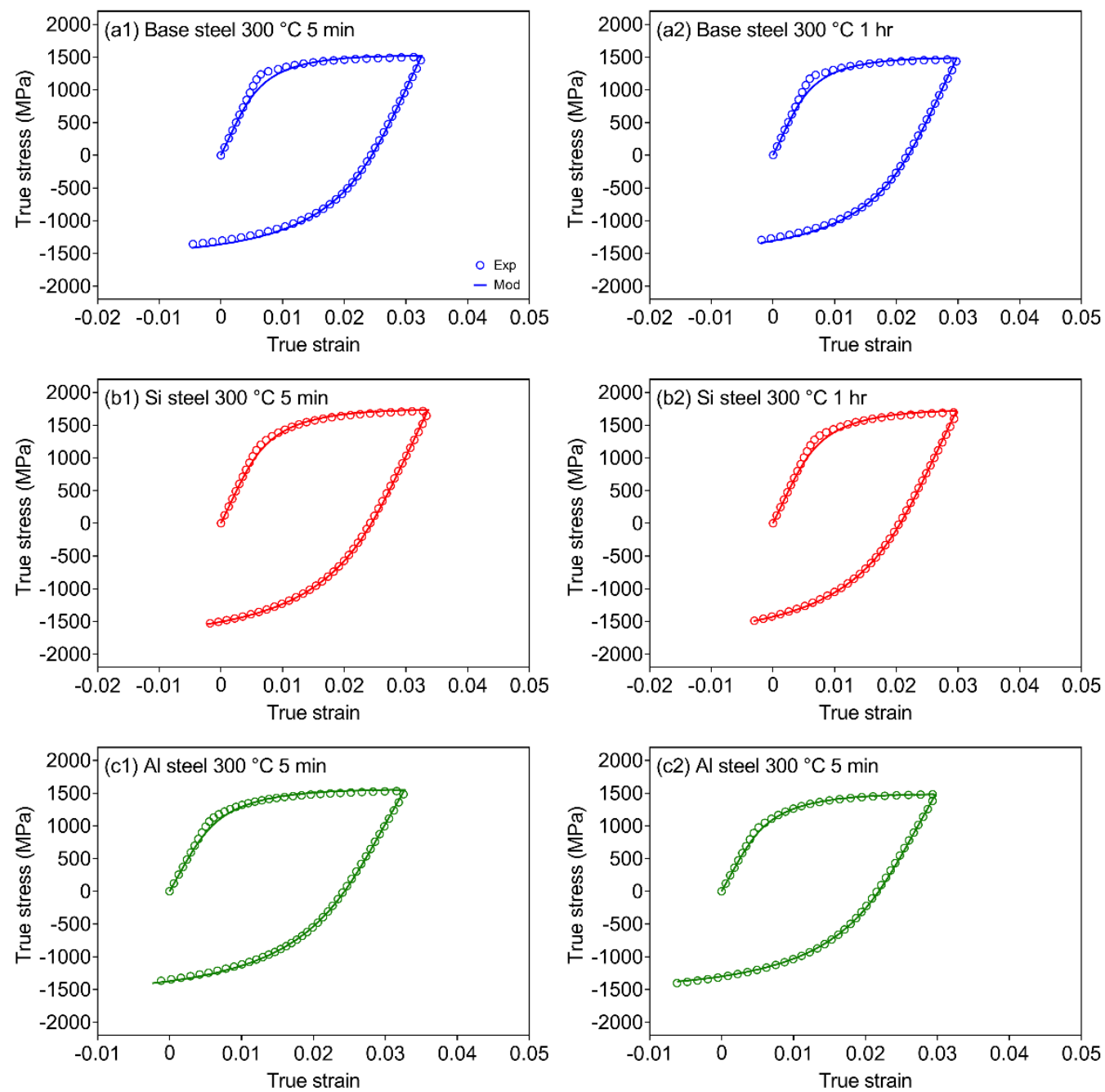

Figure A2 Experimental and modelled tension-compression curves for samples tempered at $300{ }^{\circ} \mathrm{C}$ for 5 minutes and 1 hour. 

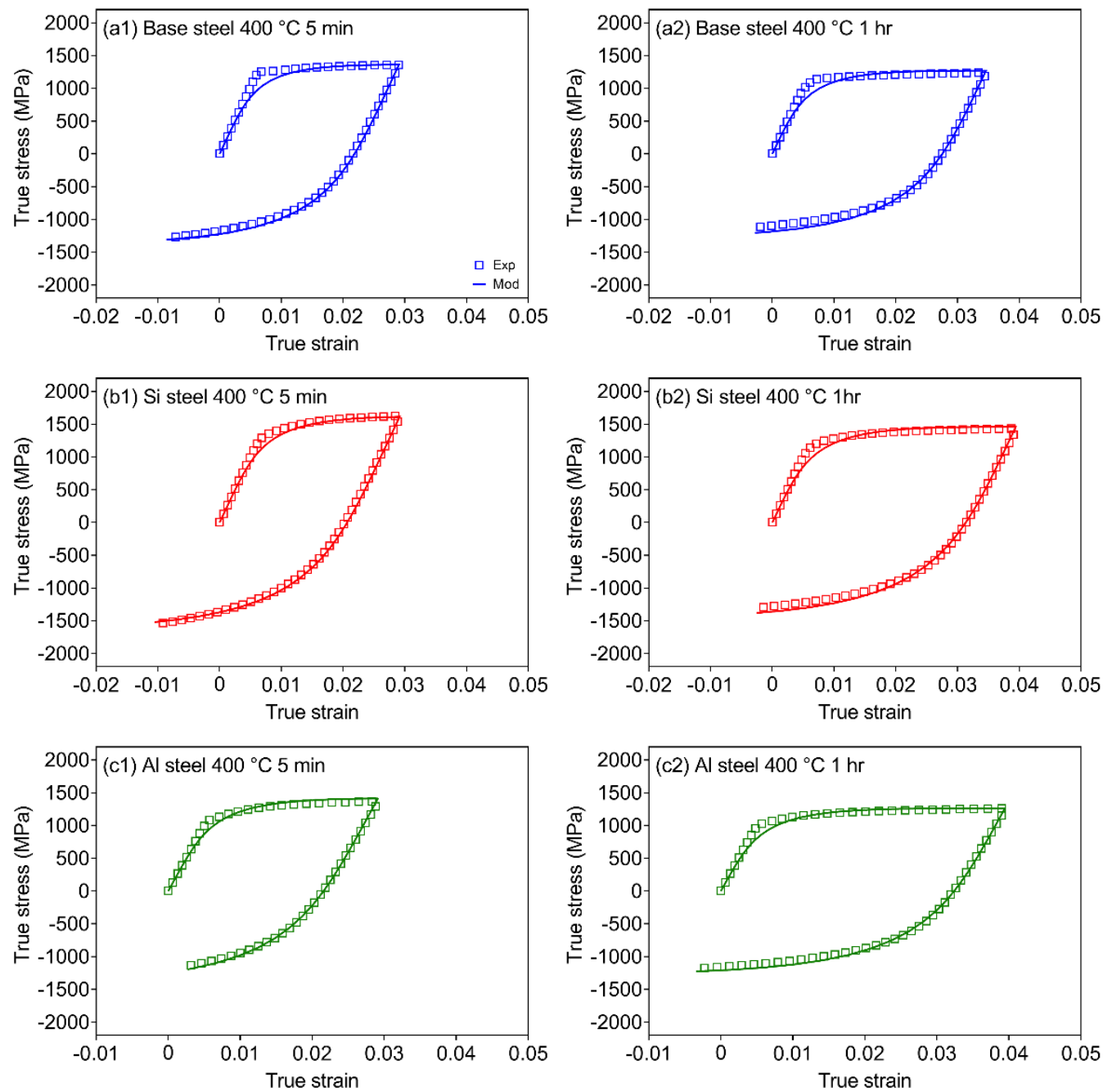

Figure A3 Experimental and modelled tension-compression curves for samples tempered at $400{ }^{\circ} \mathrm{C}$ for 5 minutes and 1 hour.

\section{Appendix B}

We have performed compression-tension tests on tempered samples and estimate the influence of the S-D effect on the flow curves obtained. Figure B1a - c shows the tension-compression (T-C) and compressiontension (C-T) test results of samples tempered at $300{ }^{\circ} \mathrm{C}$ for 5 minutes. The flow stress in compression is indeed larger and it is true for both the forward and reverse loadings. In the case of forward loading the compression forward loading results in higher flow stress than tension and the difference between the two curves keeps relatively constant with strain. In the case of the flow stress after strain reversal, the compression curve is higher than the tension curve as well. This indicates the Bauschinger effect obtained using the T-C test may serve as a lower bound and the one obtained with the C-T test may be the upper bound. However, the overall trends of the flow curves do not differ significantly, suggesting the omission of the S-D effect in the "integral composite model" should not affect the simulated elastic-plastic transitions in both tension and compression shown in Figure 10. 

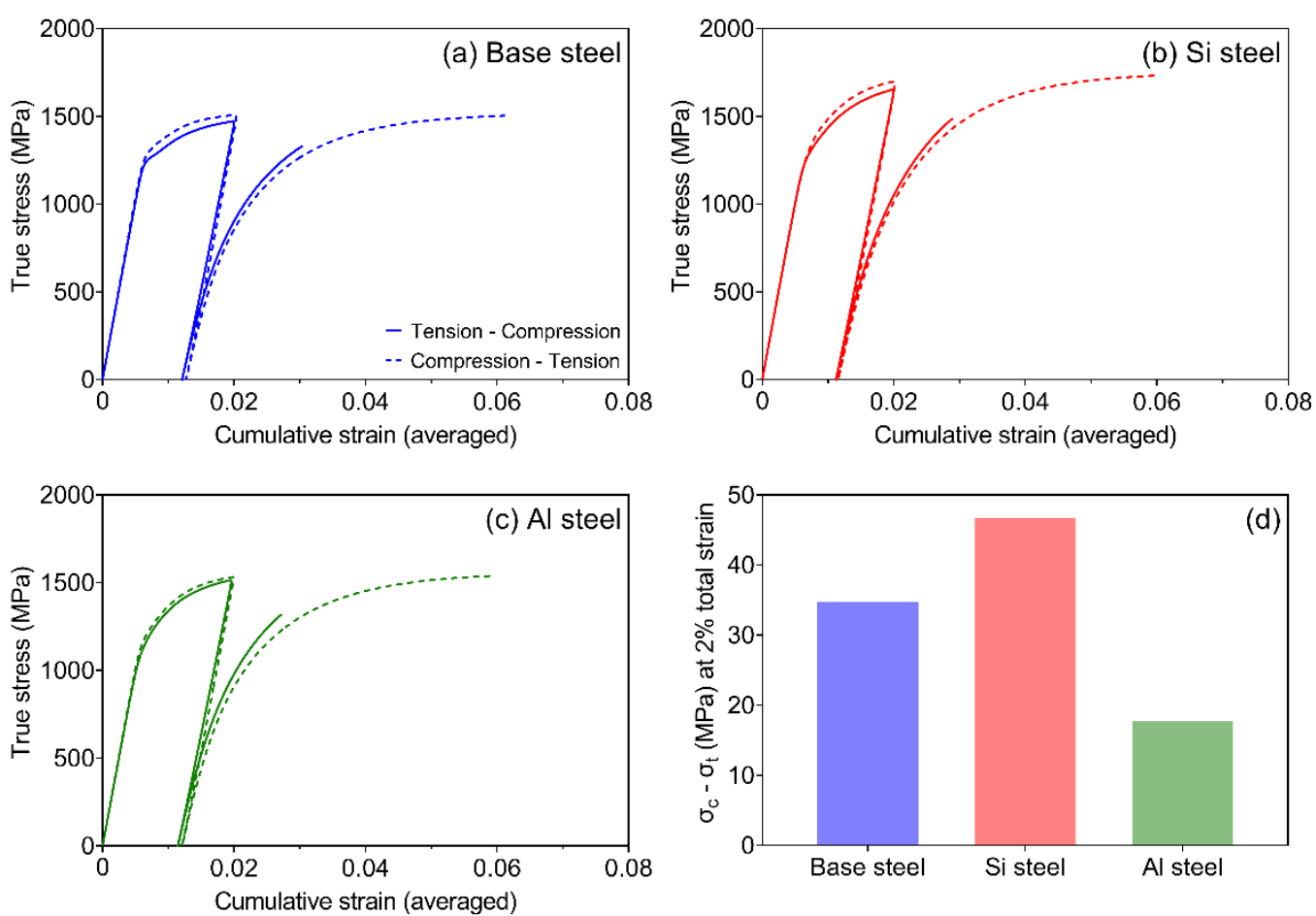

Figure B1 Comparison between the compression-tension (C-T) and the tension-compression (T-C) tests. (a) - (c) Strain reversal curves for samples tempered at $300{ }^{\circ} \mathrm{C}$ for 5 minutes. (d) The difference between the forward flow stresses when tensioned or compressed to $2 \%$ total strain.

The difference between the forward flow stresses in compression $\left|\sigma_{c}\right|$ and in tension $\left|\sigma_{t}\right|$ at $2 \%$ total strain is approximately $30-40 \mathrm{MPa}$ (Figure B1d), the lower difference in the Al steel could be a result of sample-tosample variation. The S-D effect is often quantified as the ratio between the difference in flow stress and the average flow stress:

$$
S-D=2 \frac{\left|\sigma_{c}\right|-\left|\sigma_{t}\right|}{\left|\sigma_{c}\right|+\left|\sigma_{t}\right|}
$$

In the case of $300{ }^{\circ} \mathrm{C}$ tempered samples, the S-D ratio is $\sim 3 \%$. This value decreased to $\sim 1.5 \%$ or less in the case of $500{ }^{\circ} \mathrm{C}$ samples. This is consistent with results found in the literature which suggested the S-D effect could be reduced by tempering at high temperatures $[58,68,75]$. We have not performed C-T tests on asquenched samples but the magnitude of the strength differential could be estimated as $~ 170 \mathrm{MPa}$ by averaging the values found in $4320(\sim 130 \mathrm{MPa})$ and $4340(\sim 200 \mathrm{MPa})$ steels [70]. This value would result in a S-D ratio $\sim 8 \%$ in the studied steels and agree with the typical S-D ratios found in as-quenched samples [70].

Apart from the magnitude of the Bauschinger effect, another concern associated with the S-D effect is if its omission could significantly affect the modelled tension-compression curves, especially in the case of the "yield stress spectrum model" and the "integral composite model" for the modelling of as-quenched samples where the S-D effect is the largest. To incorporate the S-D effect into the existing models, we adopted an anisotropic yielding criterion which allows the yield stresses in tension and compression to be different: 


$$
\begin{aligned}
\sigma_{y}^{t} & =\frac{c}{1+a} \\
\sigma_{y}^{t} & =\frac{c}{1-a}
\end{aligned}
$$

where $c$ is the strength coefficient and $a$ is the differential coefficient which can be estimated using the S-D ratio as:

$$
2 a=S-D
$$

This yielding criterion was first introduced in the work of Spitzig and Richmond [76] based on the yielding criterion proposed by Drucker and Prager for pressure dependant flow behaviours [77].

For as-quenched martensite, $a$ can be found as 0.04 which is one half of the estimated $S-D$ ratio. The yield stresses for constituents in compression can be calculated as:

$$
\sigma_{y}^{c}=\sigma_{y}^{t} \times \frac{1+a}{1-a}
$$

where $\sigma_{y}^{t}$ for each constituent are known values from the "yield stress spectrum model" and the "integral composite model" once the mean and the standard deviation are optimised. In the case of the "integral composite model", it is the yield stress obtained after the relaxation of residual stress that is enhanced in compression, not the apparent local yield stress at the beginning.

Figure B2a shows the effect of the S-D effect on the modelled results for the "yield stress spectrum model". The yield stress spectrum was optimised based on the tensile curve of the as-quenched Si steel sample (i.e. the same spectrum used in Figure 6c). While a large discrepancy was observed in the model without the S-D effect, the inclusion of the S-D effect can indeed make the agreement in the compression part better. However, it should be emphasised that the S-D effect may not be the first order effect since the same discrepancy was observed in shear-reversal and torsion-reversal tests where no S-D effect should be expected $[17,40]$. The main reason for the underestimated reverse flow stress should be primarily attributed to the lack of residual stress relaxation terms in the original "yield stress spectrum model", which was addressed in the newly proposed "integral composite model".
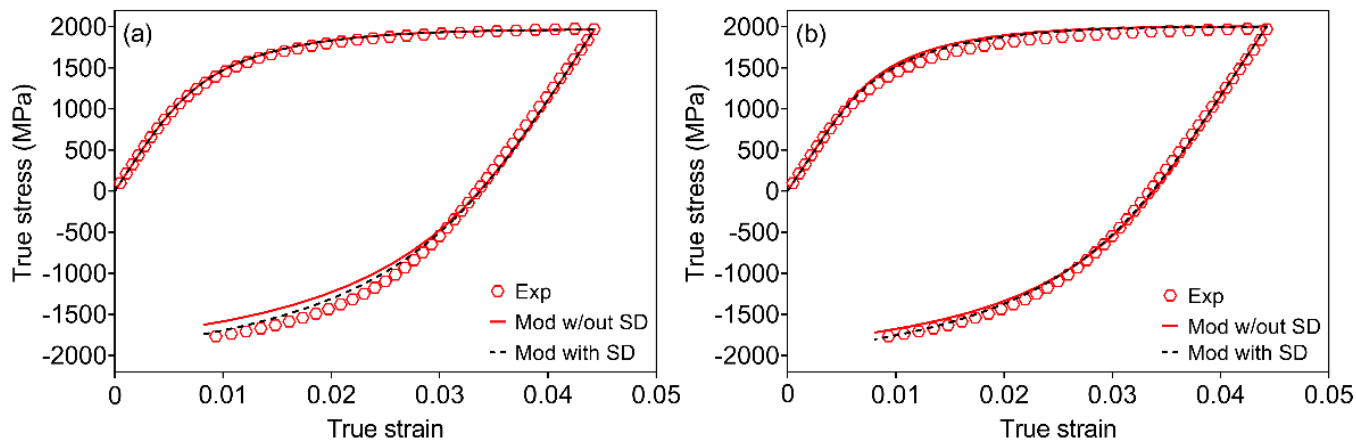

Figure B2 The effect of the S-D effect on the modelled results for the as-quenched Si steel sample in the case of the "yield stress spectrum model" (a) and the "integral composite model". 
Figure B2b shows the effect of the S-D effect on the modelled results for the "integral composite model". The initial apparent yield stress spectra were optimised separately for the model with and without the S-D effect (only the $\sigma_{s d}^{0}$ was optimised, $\sigma_{\mu}$ and $\alpha_{r}$ were kept the same in both cases). Although the inclusion of the S-D effect could improve the agreement of the modelled curve during reverse loading, the effect is not as significant as the one observed in the "yield stress spectrum model". Therefore, the inclusion of the residual stress relaxation in the "integral composite model" and the optimisation of the $\sigma_{s d}^{0}$ parameter may readily reproduce a relatively good tension-compression flow behaviour without considering the S-D effect. 